\title{
Financial Contagion and Attention Allocation
}

\author{
Jordi Mondria* \\ Princeton University ${ }^{\dagger}$
}

First draft: December 2004

This draft: November 2005

\begin{abstract}
This paper explains financial contagion between two independent stock markets by fluctuations in international investors' attention allocation. I model the process of attention allocation that underlies portfolio investment in international markets using rationally inattentive agents. Investors optimally allocate more attention to a region hit by a financial crisis, to the detriment of other markets. The resulting endogenous increase in uncertainty causes the risk premium on all risky assets to rise. Hence, stock prices around the world collapse and there is a flight to quality. I show that the degree of (non)anticipation of a crisis is crucial for the existence of contagion. Using Financial Times coverage as a proxy for attention allocation, I find strong support for the model's predictions.
\end{abstract}

*Department of Economics, Princeton, NJ 08544. E-mail: jmondria@princeton.edu.

†I am indebted to my advisor Hélène Rey for her advice and countless suggestions that made this work possible. I also want to express my gratitude to Chris Sims for his intellectual influence. I benefited from comments and discussions with Kevin Amonlirdviman, Markus Brunnermeier, Carlos Carvalho, Vasco Cúrdia, Wiola Dziuda, Rodrigo Guimaraes, Per Krusell, Pete Kyle, Ulrich Müller, Jonathan Parker, Wolfgang Pesendorfer, Climent Quintana-Domeque, Ricardo Reis, Stijn Van Nieuwerburgh, Laura Veldkamp, Noah Williams, Thomas Wu, Wei Xiong and all the seminar participants at Princeton student seminars, Econometric Society World Congress 2005 and Congress of the European Economic Association 2005. I gratefully acknowledge financial support from Fundación Rafael del Pino. All remaining errors are mine. 


\section{Introduction}

International financial markets have suffered many crises over the last decade. These episodes have not been concentrated in a particular country or region, but have caused severe repercussions in the international capital markets. The Asian crisis erupted in Thailand with the devaluation of the Thai baht on July 2, 1997, and in a few months, the crisis spread to Philippines, Malaysia, Indonesia, Hong Kong, Korea, Japan and Singapore. North and South American, European and African stock markets were affected after events in East Asia became headline news in American and British newspapers in mid-October. The Russian crisis, which started with the default of the Russian government on its sovereign bonds on August 18, 1998, and the later public knowledge that the hedge fund Long Term Capital Management (LTCM) had gone bankrupt, generated a "fast and furious $1 "$ contagious episode that spread to most emerging and developed markets. Hong Kong, Brazil and Mexico were the most affected countries.

Financial contagion refers to the comovement of exchange rates, stock prices and capital flows in one market as a result of a financial crisis in another market. The pattern of comovement across countries is still puzzling even though several transmission channels have been studied. Bilateral and third party trade links were examined by Kaminsky and Reinhart (1999), who showed that these links are more relevant in Latin America than in East Asia. Kaminsky, Reinhart and Vegh (2003) reported that Russia's trade with other countries affected by the Russian virus was very limited and that in many crises without contagion, there were strong trade links. In Kaminsky and Reinhart (1999) and Kodres and Pritsker (2002), contagion occurs among countries that are directly or indirectly linked through cross market-hedging when investors have

\footnotetext{
${ }^{1}$ Term used by Kaminsky, Reinhart and Vegh (2003) to describe the immediate adverse chain reaction that some financial events cause to other international financial markets.
} 
a globally diversified financial portfolio. This transmission mechanism implies that prices fall in several countries, while increasing in others. However, when financial contagion arises, the financial crisis spreads to all international financial markets. Correlated information shocks as in King and Wadhwani (1990), where price movements in one country are perceived as having implications for price changes in other markets, are only plausible for countries whose fundamentals are strongly linked. Correlated liquidity shocks as in Calvo (1999), where margin calls force investors to liquidate their assets, may generate contagion across the most liquid markets, but it is less clear that this explanation holds for emerging markets. In his model, uninformed investors misread the margin calls to informed investors by interpreting them as low returns in emerging markets. Allen and Gale (2000) study financial contagion caused by linkages among financial intermediaries. In Calvo and Mendoza (2002), globalization generates rational herding by decreasing the incentives of investors to process costly information. Kyle and Xiong (2001) study contagion in a theoretical model where there is an increase in risk aversion due to a wealth effect from the financial intermediaries. Yuan (2000) develops a rational expectations model of asset prices, where contagion arises from the interaction between asymmetric information and borrowing constraints. Kaminsky and Reinhart (1999) and Kaminsky, Reinhart and Vegh (2003) also explain contagion within regions by the existence of a single common creditor. However, this channel is not able to explain contagion between regions.

The aim of this paper is to provide a new mechanism through which financial crises are transmitted within and between regions. The model explains financial contagion as an increase in uncertainty and a price drop in one market as a consequence of a financial crisis in another independent market due to attention reallocation over short periods of time. In times of financial crises, the amount of daily news, rumors and investor 
concerns increases dramatically. Investors optimally reallocate their limited capacity to process information to the region hit by the financial crisis, i.e., they allocate more resources to process information about the shaken stock market, to the detriment of other independent stock markets. This results in an endogenous increase in volatility around the world and a collapse of international stock prices. Although other channels may be important for shedding light on contagion, this paper studies a new financial transmission mechanism where, provided investors have a limited capacity to process information, contagion between two independent international stock markets arises even in the absence of correlated information shocks, correlated liquidity shocks, direct or indirect macroeconomic links and borrowing constraints.

The model of contagion presented in this paper is a multiple asset, noisy rational expectations model with rationally inattentive agents that builds on Admati (1985) and Peng and Xiong (2005). The framework consists of two independent risky assets, which are interpreted as the national stock market indexes of two countries or regions. There is a continuum of agents who face information capacity constraints as in Sims (2003, 2005). Each agent tries to obtain information about both stock markets in order to reduce the uncertainty of her optimal portfolio. However, investors have a limited capacity to process information, which they need to allocate between the two risky assets. Investors optimally choose their private signal given their information processing constraint. After allocating their attention, investors incorporate the information from their private signal and prices through Bayesian updating to form their posterior beliefs about the asset payoffs and choose their optimal asset holdings. Investors optimally process more information about the region hit by a financial crisis. Hence, the posterior beliefs about other emerging markets become less precise. The resulting endogenous decrease in the capacity of bearing risks by international investors induces them to 
liquidate their positions in all risky assets. As a consequence, there is a reduction of market liquidity that leads to an increase in price volatility and a collapse of asset prices in all emerging markets.

These results are supported by the empirical evidence provided in Section 6 , where news coverage in the Financial Times is used as a proxy for attention allocation. An increase in asset payoff volatility in Thailand generates an increase in the number of news articles in the Financial Times about Thailand, which is a proxy for an increase in attention allocated to Thailand. This leads to an increase of the volatility in the Latin American stock markets because of the reduction on the attention allocated to process information about those countries.

This paper is also related to the theoretical literature on rational inattention applied to finance. Peng (2005) and Peng and Xiong (2005) are the first attempts at introducing information capacity constraints into finance. However, prices reveal all the private information in their approach. They also assume independence of uncertainty across fundamental factors both ex ante and ex post, which means that investors collect information about each factor separately. Van Nieuwerburgh and Veldkamp (2005a, 2005b) generalize the model by introducing a random asset supply ${ }^{2}$. Hence, prices are not fully revealing in equilibrium. In their setup, if assets are independent, investors process information about only one of the assets because the ex post variance of the payoffs is constrained to be diagonal. In other words, their approach keeps the independent sources of uncertainty still independent ex post as in Peng (2005) and Peng and Xiong (2005). In contrast, the approach of rational inattention to finance that I am presenting finds the optimal form of the ex post variance of the payoffs, which is not initially constrained to be diagonal. Investors optimally choose to observe a linear combination of

\footnotetext{
${ }^{2}$ This paper started as an independent project from Van Nieuwerburgh and Veldkamp (2005a, 2005b).
} 
assets payoffs as a private signal. Gabaix and Laibson (2001), Mankiw and Reis (2002, 2003) and Reis $(2004,2005)$ present an alternative way of modelling inattentiveness, where agents infrequently update their information sets and plans. In their approach, agents obtain perfect information at certain dates and remain uninformed the rest of the time, while in the rational inattention approach, introduced by Sims (2003, 2005), agents obtain an imperfect signal about the state of the economy every period.

Kaminsky, Reinhart and Vegh (2003) and Rigobon and Wei (2003) provided empirical evidence that points towards the degree of (non)anticipation of a crisis as the cause of financial contagion. This is the first theoretical model, to my knowledge, that points towards the degree of (non)anticipation of a financial crisis as the explanation of why some financial crises cause severe financial contagion and why others do not. If a financial crisis suddenly hits a country, investors are taken by surprise, and they are only able to reallocate their limited information processing capacity, which causes financial contagion. However, if investors anticipate a future financial crisis, they will spend more resources to increase their limited capacity to process information so that when a financial crisis arises, less attention needs to be reallocated.

The remainder of the paper is organized as follows. In Section 2, there is a description of the model with special emphasis on rationally inattentive agents and information theory. Section 3 finds the solution to the investor's optimization problem and explains how investors allocate their attention. Section 4 discusses the financial transmission channel, which causes volatility and price comovement in the model. Section 5 provides a theoretical explanation of why some crises generate financial contagion, while others only affect the country hit by the financial crisis. Section 6 shows an empirical analysis, where news coverage in the Financial Times is used as a proxy for attention allocation and provides support for the results of the model. Section 7 concludes. The Appendix 
provides technical derivations and proofs.

\section{Model Description}

The model consists of two regions with a risky asset in each one of them. Each risky asset represents the stock market index of a separate region. There is a continuum of agents of measure one. Each agent has a limited capacity to analyze the fundamental factors that affect the stock market.

Agents live four periods. In the first period, they receive an initial wealth, $W_{i 0}$, and a limited capacity to process information, $\kappa^{3}$. In the second period, investors allocate their limited capacity to process information to analyze the different fundamental factors. In the third period, each investor decides on the optimal portfolio given the observation of a private signal, which depends on the amount of information processed about each stock market, and the price, which is public information. In the last period, agents consume the payoff of their portfolio.

Each agent invests her initial endowment in three different assets: a risk free asset that pays $R$ units of the consumption good and two independent risky assets. The region 1 risky asset is traded in the first region stock market and pays $\tilde{r}_{1} \sim N\left(\bar{r}_{1}, \sigma_{r, 1}^{2}\right)$ units of the consumption good. The region 2 risky asset is traded in the second region stock market and pays $\tilde{r}_{2} \sim N\left(\bar{r}_{2}, \sigma_{r, 2}^{2}\right)$ units of the consumption good. Let $\bar{R}$ and $\Sigma_{R}$ denote the mean vector and the diagonal variance-covariance matrix of the vector $\tilde{R}=\left(\tilde{r}_{1}, \tilde{r}_{2}\right)^{\prime}$. The numeraire in the market is the price of the bond and $\tilde{P}=\left(\tilde{p}_{1}, \tilde{p}_{2}\right)^{\prime}$ is the price vector of the risky assets. The net supply of the risky asset $j$ is given by the realization of a random variable $\tilde{z}_{j} \sim N\left(\bar{z}_{j}, \sigma_{z, j}^{2}\right)$. Let $\bar{Z}$ and $\Sigma_{Z}$ denote the mean vector and the

\footnotetext{
${ }^{3}$ I will endogenize the optimal decision of limited attention in Section 5. For now, let's assume that $\kappa$ is exogenously given as in Sims $(2003,2005)$.
} 
diagonal covariance matrix of the vector of net supply $\tilde{Z}=\left(\tilde{z}_{1}, \tilde{z}_{2}\right)^{\prime}$. This randomness can be viewed as the result of some trade of a nonspeculative nature (liquidity traders) or some trade from agents lacking perfect knowledge of the market structure (irrational traders). Asset supply randomness is necessary in order to avoid perfect revelation of private information through the price.

\subsection{Information Theory}

Investors face a technological constraint, which is called information processing constraint, that limits the amount of information they can process. Intuitively, there is a large amount of information freely available relevant for decision making, but it takes time and mental attention for an investor to incorporate this information into their decisions. Hence, investors have a limited capacity to process information that they need to allocate among both markets.

Following Sims (2003, 2005), I use concepts from information theory to quantify the amount of information that a private signal contains about the asset payoffs. Information theory ${ }^{4}$ measures the rate of information flow as the rate of uncertainty reduction. Entropy is the measure of uncertainty used to calculate the information flow. This measure of uncertainty can be derived from four reasonable axioms, see Khinchin (1957). The entropy $H(X)$ of a random variable $X$ with a continuous probability density $p(x)$ is defined as

$$
H(X)=-E \log [p(X)]=-\int p(x) \log p(x) d x
$$

In the case where $X \sim N(\bar{X}, \Sigma)$ is an n-dimensional multivariate normal, then its

\footnotetext{
${ }^{4}$ For a reference on information theory see Cover and Thomas (1991) and Reza (1994).
} 
entropy is

$$
H(X)=\frac{1}{2} \log \left((2 \pi e)^{n}|\Sigma|\right)
$$

Intuitively, for a Gaussian distributed variable, higher uncertainty is associated with higher variance. The conditional entropy of $X$ given the observation of another random variable $Y$ is written as

$$
H(X \mid Y)=-E \log [p(X \mid Y)]=-\int p(x, y) \log p(x \mid y) d x d y
$$

$H(X \mid Y)$ measures the uncertainty of a random variable $X$ given the observation of another random variable $Y$.

A measure of uncertainty reduction is needed to calculate the information flow. According to information theory, mutual information measures the amount of information that a random variable contains about another random variable. It is the reduction of uncertainty of one random variable due to the knowledge of another random variable. Consider two random variables $X$ and $Y$ with a joint probability mass function $p(x, y)$ and marginal probability mass functions $p(x)$ and $p(y)$. Mutual information $I(X ; Y)$ is defined as

$$
I(X ; Y)=\int p(x, y) \log \frac{p(x, y)}{p(x) p(y)} d x d y=H(X)-H(X \mid Y)
$$

Mutual information is invariant to any linear transformations of both random variables $X$ and $Y$

$$
I(X ; Y)=I(a X+b ; c Y+d)
$$

This measure is independent of the scale of the underlying variables (risky assets), unlike other measures of information as the precision of the error in the private signal 
as in Verrechia (1982). Given a limited information processing capacity, $\kappa^{5}$, which is the maximum rate at which agents can process information, the information processing constraint can be expressed as

$$
I(X ; Y)=H(X)-H(X \mid Y) \leq \kappa
$$

The information processing constraint limits the information flow by introducing an upper bound to the mutual information ${ }^{6}$. Intuitively, this constraint restricts the amount of information contained in the private signal.

\subsection{Rationally Inattentive Agents}

Investors want to obtain information about the risky assets in order to reduce the uncertainty of their optimal portfolio. However, agents have a limited capacity to process information about asset payoffs, which can be interpreted as limited time or mental attention. Investors face an information capacity constraint as in Sims (2003, 2005). Agents optimally decide how much information they want to process about each stock market given their limited information processing capacity and choose the form of the private signal through which they process this information. Investors are constrained to choose a signal of the following form

$$
\tilde{Y}_{i}=C_{i} \tilde{R}+\tilde{\varepsilon}_{i} \text { where } \tilde{\varepsilon}_{i} \sim N\left(0, \Sigma_{i}\right)
$$

\footnotetext{
${ }^{5}$ The information processing capacity, which is the upper bound of the mutual information, is the infomation flow measure used in, among other things, characterizing modems or internet connections.

${ }^{6} \mathrm{An}$ advantage of this measure of information is that there is no need to characterize the physical nature of the channel (wires, optical cables, human brain) through which the information is sent, it is enough to specify the capacity of the channel, $\kappa$.
} 
where $C_{i}$ is any $k \times 2$ matrix, $\tilde{\varepsilon}_{i}$ is independent of $\tilde{R}, \tilde{\varepsilon}_{i}$ is independent of $\tilde{\varepsilon}_{k}$ for $i \neq k$ and $\Sigma_{i}$ is the variance covariance matrix of $\tilde{\varepsilon}_{i}$. The private signal provides information about linear combinations of asset payoffs. The precision of a signal is higher if more attention is allocated to that particular signal. The private signals are incorporated to the investor's beliefs through rational Bayesian updating. Investors optimally find the form of the conditional variance of the payoffs, which is not initially constrained to be diagonal, by choosing $C_{i}$ and $\Sigma_{i}$ subject to the information processing constraint.

All investors have the same level of limited capacity to process information $\kappa$. They are choosing an optimal private signal in order to reduce their uncertainty about asset payoffs. Prices are perfectly observable, which means that investors are able to process information about prices for free. In this case, since prices reveal information, the random variable of interest for the investor is the asset payoff conditional on asset prices. Therefore, investors optimally choose a private signal to decrease the remaining uncertainty about asset payoffs, once prices are perfectly observed, subject to the following information processing constraint

$$
H(\tilde{R} \mid \tilde{P})-H\left(\tilde{R} \mid \tilde{P}, \tilde{Y}_{i}\right) \leq \kappa
$$

Assuming Gaussian distributions for the risky asset payoffs, the private signals and the prices, the information processing constraint can be rewritten as

$$
\ln |\operatorname{Var}(\tilde{R} \mid \tilde{P})|-\ln \left|\operatorname{Var}\left(\tilde{R} \mid \tilde{Y}_{i}, \tilde{P}\right)\right| \leq 2 \kappa
$$

The information processing constraint ${ }^{7}$ is restricting the information flow or, in other

\footnotetext{
${ }^{7}$ Agents are not allowed to process information about the net asset supply, which is not included in the information processing constraint. In other words, the cost of processing information about the net asset supply is infinite.
} 
words, the amount of information about the asset payoffs contained in the private signal.

The second constraint required for rationally inattentive agents is the "no-forgetting constraint":

$$
\operatorname{Var}(\tilde{R} \mid \tilde{P})-\operatorname{Var}\left(\tilde{R} \mid \tilde{Y}_{i}, \tilde{P}\right) \text { positive semi-definite. }
$$

Intuitively, agents are not able to forget information that they already know in order to obtain another type of information. Hence, investors are not able to increase the uncertainty of one risky asset to decrease the uncertainty of the other risky asset.

Peng (2005), Peng and Xiong (2005) and Van Nieuwerburgh and Veldkamp (2005a, 2005b) exogenously set $C_{i}$, in equation (1), to be the identity matrix ${ }^{8}$. In the case that the risky assets are ex ante independent, they assume independence of uncertainty across assets ex post, which means that investors collect separately information about each asset. In other words, they constrain the ex post variance of the payoffs to be diagonal, which means that independent sources of uncertainty are still kept independent ex post, whereas this is not necessary optimal in a portfolio problem. It implies that an agent collects information one asset at a time, so that the only way to reduce uncertainty on a broad portfolio is to reduce variance on each asset, leaving them still conditionally independent after the information collection. However, in this model, $C_{i}$ is optimally chosen by investors. Therefore, this implies, for the case of two independent assets, that it could be optimal to have as a signal a weighted sum of asset payoffs instead of only receiving a signal about each asset. In other words, investors optimally find the form of the conditional variance of the payoffs, which is not initially constrained to be diagonal.

\footnotetext{
${ }^{8}$ In Peng and Xiong (2005), dividends are linear combinations of different fundamental factors and investors observe an independent private signal about each fundamental factor.
} 


\subsection{Investor Optimization Problem}

Investors, with a constant risk tolerance parameter $\rho_{i}$, maximize their expected certainty equivalent wealth

$$
U_{i}=E\left\{-\ln E\left[\exp \left(-\frac{W_{i}^{\prime}}{\rho_{i}}\right) \mid \tilde{Y}_{i}, \tilde{P}\right]\right\}
$$

where $W_{i}^{\prime}$ is the wealth of agent $i$ in the last period. Investors have a preference for early resolution of uncertainty ${ }^{910}$ as introduced by Kreps and Porteus (1978). This is equivalent to maximizing a mean-variance objective function

$$
U_{i}=E\left(E\left[W_{i}^{\prime} \mid \tilde{Y}_{i}, \tilde{P}\right]-\frac{1}{2 \rho_{i}} \operatorname{Var}\left[W_{i}^{\prime} \mid \tilde{Y}_{i}, \tilde{P}\right]\right)
$$

These preferences are introduced because there is an unmodelled intertemporal consumption choice. If instead investors had to choose their optimal consumption each period and they had a standard expected utility, then they would have a desire for early resolution of uncertainty as suggested by Spence and Zeckhauser (1972). This intertemporal consumption decision is not modelled because it unnecessarily complicates the model. Instead, I gain tractability while maintaining a preference for early resolution of uncertainty by employing Kreps and Porteus preferences. Kreps and Porteus (1978, 1979) introduced a utility function that induces a desire for early resolution of uncertainty in the absence of an intertemporal consumption choice.

\footnotetext{
${ }^{9} \mathrm{~A}$ preference for early resolution of uncertainty is expressed with a convex aggregator over the expected utility. I use the following convex transformation in order to obtain closed form solutions $f(x)=-\ln (x)$ where $x=E\left[\exp \left(-\frac{W_{i}^{\prime}}{\rho_{i}}\right) \mid \tilde{Y}_{i}, \tilde{P}\right]$. The results of the paper are robust to other convex transformations of the form $g(x)=-\frac{(-x)^{\alpha}}{\alpha}$ for $0 \leq \alpha<1$.

${ }^{10}$ This type of utility function has been used for a dynamic stochastic optimal consumption model in Weil $(1990,1993)$ and models of robust control Hansen and Sargent $(1995,2004)$.
} 
Investors maximize their objective function subject to the budget constraint is

$$
W_{i}^{\prime}=W_{i 0} R+X_{i}^{\prime}(\tilde{R}-R \tilde{P})
$$

where $W_{i 0}$ is the initial wealth of agent $i, X_{i}=\left(x_{i, 1}, x_{i, 2}\right)^{\prime}$ is the asset holdings vector

of agent $i, \tilde{R}$ is the vector of risky asset payoffs and $\tilde{P}$ is the price vector of the risky assets. The market clearing conditions are given by $\int_{0}^{1} X_{i} d i=\tilde{Z}$.

Investors devote their limited attention to process information about the asset payoffs. After choosing the form of the private signal, investors decide the amount of information they want to process about each stock market. Then, investors incorporate the information from their optimally chosen private signal, $\tilde{Y}_{i}$, and the price into their beliefs through Bayesian updating. After investors derive their posterior beliefs about the asset payoffs, they decide their optimal asset holdings.

\section{Solving the Model}

The model is solved using backward induction. First, given an arbitrary attention allocation, each agent decides the optimal asset holdings. Second, given the optimal risky asset demand for each attention allocation, each agent decides the optimal attention allocation.

\subsection{Optimal Asset Holdings}

In the third period, each agent chooses the optimal risky asset demand taking as given any attention allocation, by using the standard definition of rational expectations equilibrium following Admati (1985). 
Definition 1 A rational expectations equilibrium is a price vector $\tilde{P}$ and allocation functions $\left\{X_{i}\left(\tilde{Y}_{i}, \tilde{P}\right)\right\}_{i \in[0,1]}$ such that: (i) $\tilde{P}$ is $(\tilde{R}, \tilde{Z})$ measurable; (ii) $X_{i}\left(\tilde{Y}_{i}, \tilde{P}\right) \in$ $\arg \max _{X_{i}} E\left[W_{i}^{\prime} \mid \tilde{Y}_{i}, \tilde{P}\right]-\frac{1}{2 \rho_{i}} \operatorname{Var}\left[W_{i}^{\prime} \mid \tilde{Y}_{i}, \tilde{P}\right]$, for each agent $i ;$ (iii) $\int_{0}^{1} X_{i}\left(\tilde{Y}_{i}, \tilde{P}\right) d i=\tilde{Z}$ almost surely.

After observing the private signals and the asset prices, investors derive their posterior beliefs about the asset payoffs in order to choose their optimal asset holdings

$$
X_{i}\left(\tilde{Y}_{i}, \tilde{P}\right)=\rho_{i} \operatorname{Var}\left[\tilde{R} \mid \tilde{Y}_{i}, \tilde{P}\right]^{-1} E\left[\tilde{R}-R \tilde{P} \mid \tilde{Y}_{i}, \tilde{P}\right]
$$

The rational expectations equilibrium price is found by aggregating these asset demands and imposing the market clearing conditions.

Proposition 1 There exists a unique linear rational expectations equilibrium price. It depends on both market aggregates

$$
\tilde{P}=A_{0}+A_{1} \tilde{R}-A_{2} \tilde{Z} \text {, with } A_{2} \text { nonsingular }
$$

Expressions for $A_{0}, A_{1}$ and $A_{2}$ are in the appendix. The conditional distribution of $\tilde{R}$ given a private signal $\tilde{Y}_{i}$ and the equilibrium price vector $\tilde{P}$ is a multivariate normal with expectation

$$
E\left[\tilde{R} \mid \tilde{Y}_{i}, \tilde{P}\right]=B_{0 i}+B_{1 i} \tilde{Y}_{i}+B_{2 i} \tilde{P}
$$

and variance-covariance matrix

$$
V_{i}=\operatorname{Var}\left[\tilde{R} \mid \tilde{Y}_{i}, \tilde{P}\right]=\left(\Sigma_{R}^{-1}+\Pi \Sigma_{Z}^{-1} \Pi+C_{i}^{\prime} \Sigma_{i}^{-1} C_{i}\right)^{-1}
$$

Expressions for $B_{0}, B_{1}$ and $B_{2}$ are in the appendix. The optimal asset holdings by an 
investor $i$, who observes the state of the world with a private signal $\tilde{Y}_{i}$ and the equilibrium price vector $\tilde{P}$, are given by

$$
X_{i}\left(\tilde{Y}_{i}, \tilde{P}\right)=G_{0 i}+G_{1 i} \tilde{Y}_{i}-G_{2 i} \tilde{P}
$$

Expressions for $G_{0}, G_{1}$ and $G_{2}$ are in the appendix.

A mean variance objective function implies a linear demand for risky assets, which does not depend on wealth. If agents only face the asset holdings decision given exogenous and independent private signals, then prices and asset holdings are independent of each other. Therefore, changes in one stock market would not have any effect in other stock markets and there would not be contagion since the matrices $A_{1}$ and $A_{2}$ in the equilibrium price equation (3) would be diagonal. However, the optimal attention allocation decision will cause volatility and price comovements.

\subsection{Attention Allocation}

In the second period, each agent chooses the optimal attention allocation by maximizing her objective function taking into account the optimal asset demand. Since agents' asset holdings are affected by private information, then each investor can obtain information from observing the market clearing price when the information is dispersed among agents. After choosing the optimal attention allocation, each investor receives the private signals and observes the prices that are used to form posterior beliefs about the future payoffs.

Agents can compute the expected utility in the second period when investors know their optimal asset holdings for any attention allocation in the third period. 
Proposition 2 The objective function in the second period is given by

$$
\max _{C_{i}, \Sigma_{i}^{-1}} \operatorname{Tr}\left(V_{i}^{-1} Q\right)+E R^{\prime} V_{i}^{-1} E R
$$

where $V_{i}$ is given by equation (4) and

$$
\begin{aligned}
E R & =E\left[E\left(\tilde{R} \mid \tilde{Y}_{i}, \tilde{P}\right)-R \tilde{P}\right]=\bar{R}-R \bar{P}=\left(\bar{\rho} \Sigma_{R}^{-1}+\bar{\rho} \Pi \Sigma_{Z}^{-1} \Pi+\Pi\right)^{-1} \bar{Z} \\
Q & =\operatorname{Var}\left(E\left[\tilde{R} \mid \tilde{Y}_{i}, \tilde{P}\right]-R \tilde{P}\right)+V_{i}
\end{aligned}
$$

The information capacity constraint is given by

$$
\ln |\operatorname{Var}(\tilde{R} \mid \tilde{P})|-\ln \left|\operatorname{Var}\left(\tilde{R} \mid \tilde{Y}_{i}, \tilde{P}\right)\right| \leq 2 \kappa
$$

where $\operatorname{Var}\left(\tilde{R} \mid \tilde{Y}_{i}, \tilde{P}\right)$ is given by equation (4) and

$$
\operatorname{Var}(\tilde{R} \mid \tilde{P})=\left(\Sigma_{R}^{-1}+\Pi \Sigma_{Z}^{-1} \Pi\right)^{-1}
$$

The "no-forgetting constraint" implies

$$
\operatorname{Var}(\tilde{R} \mid \tilde{P})-\operatorname{Var}\left(\tilde{R} \mid \tilde{Y}_{i}, \tilde{P}\right) \text { positive semi-definite }
$$

The attention allocation decision consists of choosing $C_{i}$ and $\Sigma_{i}$ of the private signal in equation (1) subject to the information processing constraint and the no-forgetting constraint. Notice that $C_{i}$ is a $k \times 2$ matrix. By choosing $C_{i}$, the investor is also choosing $k$, the number of rows in $C_{i}$, which constrains the variance covariance matrix of the errors in the private signals, $\Sigma_{i}$, to be a $k \times k$ matrix. 
Proposition 3 Each investor allocates all of the limited information processing capacity to learn about one linear combination of asset payoffs. Hence, $C_{i}$ is a $1 \times 2$ matrix.

Investors process information about their portfolio as a whole instead of processing information about each of the assets included in it $^{11}$. Investors are interested in reducing the uncertainty of their state variable, which is a linear combination of asset payoffs. Intuitively, given their investment strategy in the next period, which is to hold a diversified portfolio, the relevant information is about a linear combination of assets. In practice, there are many information aggregation devices available. People invest in mutual funds some of which specialize in broad sectors, and economic news about the economy as a whole and about sectors is provided regularly in business publications.

Since $C_{i}=\left(c_{1 i}, c_{2 i}\right)$ is a $1 \times 2$ matrix, then $\Sigma_{i}^{-1}$ is a scalar. A constraint on $C_{i}$ is needed because the investor only cares about the relative weight that each asset has in the private signal. Therefore, I normalize $c_{1 i}$ to be equal to $1, C_{i}=\left(1, c_{2 i}\right)$. Hence, investors choose the optimal $c_{2 i}$, which determines the relative weight of each asset in the private signal and the private information processed about each asset.

Proposition 4 There are two imperfect information symmetric equilibria in which investors allocate all their attention to learn about one linear combination of asset payoffs, $C=\left(1, c_{2}^{*}\right)$ $c_{2}^{*}=\frac{\left(\sigma_{r 2}^{2} \sigma_{z 2}^{2}+\sigma_{r 2}^{2} \bar{z}_{2}^{2}-\sigma_{r 1}^{2} \sigma_{z 1}^{2}-\sigma_{r 1}^{2} \bar{z}_{1}^{2}\right)+\sqrt{\left(\sigma_{r 2}^{2} \sigma_{z 2}^{2}+\sigma_{r 2}^{2} \bar{z}_{2}^{2}-\sigma_{r 1}^{2} \sigma_{z 1}^{2}-\sigma_{r 1}^{2} \bar{z}_{1}^{2}\right)^{2}+4 \sigma_{r 1}^{2} \sigma_{r 2}^{2} \bar{z}_{1}^{2} \bar{z}_{2}^{2}}}{2 \sigma_{r 2}^{2} \bar{z}_{1} \bar{z}_{2}}$

\footnotetext{
${ }^{11}$ This result is also consistent with Luo (2005), where he found that in an economy with two state variables, agents want to process information about the relevant linear combination of state variables.
} 
and investors choose $\Sigma_{i}$ to be either

$$
\begin{aligned}
\Sigma^{H}= & \frac{\left(\sigma_{r 1}^{2}+c_{2}^{* 2} \sigma_{r 2}^{2}\right)+\sqrt{\left(\sigma_{r 1}^{2}+c_{2}^{* 2} \sigma_{r 2}^{2}\right) \Delta}}{2\left(e^{2 \kappa}-1\right)} \\
& o r \\
\Sigma^{L}= & \frac{\left(\sigma_{r 1}^{2}+c_{2}^{* 2} \sigma_{r 2}^{2}\right)-\sqrt{\left(\sigma_{r 1}^{2}+c_{2}^{* 2} \sigma_{r 2}^{2}\right) \Delta}}{2\left(e^{2 \kappa}-1\right)}
\end{aligned}
$$

which exist as long as

$$
\begin{gathered}
\Delta \geq 0 \\
Q_{12}>-\bar{Q}
\end{gathered}
$$

where

$$
\Delta=\sigma_{r 1}^{2}+c_{2}^{* 2} \sigma_{r 2}^{2}-4 \rho^{2}\left(e^{2 \kappa}-1\right)^{2}\left(\frac{1}{\sigma_{z 1}^{2}}+\frac{c_{2}^{* 2}}{\sigma_{z 2}^{2}}\right)
$$

Expressions for $\alpha, \beta, \gamma, e r_{1}, e r_{2}, Q_{11}, Q_{12}, Q_{22}$ and $\bar{Q}$ are also in the appendix.

There are two imperfect information symmetric equilibria. In both equilibria, investors choose $c_{2}^{*}$, which means that they allocate their attention in the same way in every equilibria. However, there are two different precision of the error in the private signal consistent with a symmetric equilibrium.

Proposition 5 There exists a perfect information equilibrium where investors choose $\Sigma_{i}=0$ and the equilibrium price vector becomes $\tilde{P}=\frac{\tilde{R}}{R}$.

If prices are fully revealing, then investors are able to choose $\Sigma_{i}=0$ without violating the information constraint. If all investors have perfect information, $\Sigma_{i}=0$, then prices are fully revealing. Therefore, the information constraint is never binding and there is no uncertainty about the asset payoffs given perfectly revealing prices. There are three attention allocation equilibria in the model (two imperfect symmetric equilibria and a 
perfect information equilibrium) that differ from each other only in the precision of the private signal.

Definition 2 An attention allocation equilibrium $\left(c_{2}^{*}, \Sigma\right)$ is stable if and only if investors have incentives to return to the equilibrium when there is a small perturbation.

An attention allocation equilibrium is unstable if and only if investors have incentives to deviate from the equilibrium when a positive measure of investors choose small deviations from $\Sigma$.

Proposition 6 The imperfect information equilibrium $\left(c_{2}^{*}, \Sigma^{L}\right)$ is unstable, while the imperfect information equilibrium $\left(c_{2}^{*}, \Sigma^{H}\right)$ and the perfect information equilibrium are stable.

Figure 1 shows the three equilibria for every variance in the first stock market, taking as given the rest of the parameters. Therefore, for a given $\sigma_{r, 1}^{2}$, there are three equilibria for the variance of the error in the private signal, $\Sigma_{i}$, which are the stable imperfect equilibrium with $\Sigma^{H}$, the unstable imperfect equilibrium with $\Sigma^{L}$ and the perfect information equilibrium with $\Sigma=0$ as long as constraints in equations (9) and (10) are satisfied. In the case that these constraints are not satisfied, there exists only a perfect information equilibrium.

Define $\Sigma_{-i}$ as the variance of the error in the private signal of all investors except for investor $i$. Then, the optimal variance of the error in the private signal for investor $i, \Sigma_{i}$, can be written as

$$
\Sigma_{i}=\frac{\sigma_{r 1}^{2}+c_{2}^{* 2} \sigma_{r 1}^{2}}{\left(e^{2 \kappa}-1\right)\left[1+\left(\sigma_{r 1}^{2}+c_{2}^{* 2} \sigma_{r 1}^{2}\right)\left(\frac{\rho^{2}}{\sigma_{z 1}^{2}}+\frac{\rho^{2} c_{2}^{* 2}}{\sigma_{z 2}^{2}}\right) \Sigma_{-i}^{-2}\right]}
$$


which implies that

$$
\begin{aligned}
& \text { If } \Sigma^{L}<\Sigma_{-i}<\Sigma^{H} \Longrightarrow \Sigma_{i}>\Sigma_{-i} \\
& \text { If } \Sigma_{-i}<\Sigma^{L} \Longrightarrow \Sigma_{i}<\Sigma_{-i} \\
& \text { If } \Sigma^{H}<\Sigma_{-i} \Longrightarrow \Sigma_{i}<\Sigma_{-i}
\end{aligned}
$$

This means that equilibria where investors choose $\Sigma^{H}$ and $\Sigma=0$ are stable. The role of the unstable equilibrium is to separate the region of convergence between the stable imperfect information equilibrium and the perfect information equilibrium. The higher the uncertainty about fundamentals, the lower the variance of private signal, $\Sigma^{L}$, in the unstable equilibrium and the smaller is the region of convergence towards the perfect information equilibrium. Therefore, the higher is the uncertainty about financial markets, the larger is the region of convergence towards the stable imperfect information equilibrium. In the case where investors are endowed with limited information processing capacity that is large relative to the uncertainty in the financial markets, then the constraint in equation (9) is not satisfied and there exists only a perfect information equilibrium. Intuitively, if investors have a large limited capacity to process information, then investors can reduce their uncertainty about fundamentals by a large amount. This implies that prices are even more informative than before, which leads investors to possibly reduce even more of their uncertainty about asset payoffs. Therefore, the perfect information equilibrium is unique when the limited information processing capacity is large.

An imperfect information symmetric equilibrium exists when the uncertainty about asset payoffs and asset supplies in the financial markets is high relative to the risk tolerance and limited capacity to process information of the investors, which is when 
parameter constraint (9) is satisfied. If investors can process enough information about fundamentals relative to its volatility, then an imperfect equilibrium does not exist. However, if the international financial markets are highly volatile relative to the limited capacity of analyzing fundamentals, then there exists an imperfect information equilibrium. The parameter constraint is a necessary condition for the existence of an imperfect symmetric equilibrium. There is another parameter constraint (10), which must be satisfied in order to have an imperfect information symmetric equilibrium. This constraint restricts $Q_{12}$ from being too negative. $Q_{12}$ is the covariance between excess returns of both risky assets. In the case that $Q_{12}$ is too negative, this means that investors can create a well diversified portfolio, which would effectively reduce the uncertainty that investors have about the world economy. This constraint is more difficult to satisfy the more similar the risky assets and the higher the limited capacity to process information of investors since they are more able to diversify risk in this case. However, the higher the uncertainty about the asset payoffs and the asset supplies the more satisfied is the constraint. Summarizing, the two parameter constraints needed to have an imperfect information equilibrium require enough uncertainty in the international capital markets.

Proposition 7 An asymmetric equilibrium does not exist.

Specialization does not arise in this model unlike in Van Nieuwerburgh and Veldkamp (2005a, 2005b). In their model, when risky assets are independent, a fraction of investors allocates all of their attention to the first asset and the rest of the agents pay attention only to the second stock market. Therefore, in their setup increasing returns to information dominates diversification. In contrast, here, by introducing a more general form of private signals as in equation (1), investors exploit both increasing returns to information processing and diversification. 


\subsection{Comparative Static Results}

Investors receive a private signal, $\tilde{Y}=\tilde{r}_{1}+c_{2}^{*} \tilde{r}_{2}+\tilde{\varepsilon}$. Hence, the attention allocated to the first market relative to the attention allocated to the second market is given by $\frac{\sigma_{r, 1}^{2}}{c_{2}^{* 2} \sigma_{r, 2}^{2}}$.

Proposition 8 Investors allocate more attention to first stock market, the higher the volatility of payoffs, $\sigma_{r, 1}^{2}$, and supply, $\sigma_{z, 1}^{2}$, in the first risky asset and the lower the volatility of payoffs, $\sigma_{r, 2}^{2}$, and supply, $\sigma_{z, 2}^{2}$, in the second stock market.

An increase in the volatility of payoffs or asset supply increases the relative attention allocated to that market, which means that more information is processed about that market. However, an increase of uncertainty about the first stock market generates a reduction of relative attention to the second stock market. An increase in the mean of the asset supply generates an ambiguous effect on the attention allocation. The reason is that an increase in the supply of one risky asset increases the aggregate risk of investors for that risky asset and more attention is allocated to the asset. On the other hand, a higher asset supply decreases asset prices and leads to a decrease in the attention allocated to the asset. An increase in the risk tolerance of investors, $\rho$, does not change $c_{2}^{*}$, but decreases $\Sigma^{H}$. If investors in the economy become more risk tolerant, then prices reveal more information since investors react more to private signals. Therefore, $\Sigma^{H}$ falls because prices reveal more information. An increase in the limited capacity to process information, $\kappa$, does not affect $c_{2}^{*}$, but decreases $\Sigma^{H}$ because investors are able to reduce more uncertainty through the information capacity constraint. 


\subsection{Unlearnable Risk}

The previous section assumes that information is freely available, but investors have a limited capacity to process this information. If investors have a large capacity to process information relative to the uncertainty in the financial markets, the constraint in equation (9) is not satisfied and there exists only a perfect information equilibrium. However, in reality, even if they have a large capacity to process information, investors are not able to reduce all the uncertainty about financial markets. In this section, the specification of the model remains unchanged, but unlearnable risk is introduced in two different ways:

\subsubsection{Unlearnable risk as an independent constraint}

Unlearnable risk is modelled as a constraint in the variance covariance matrix of asset payoffs given prices and private signals, $V_{i}$. The objective function in Proposition 2 and the information constraint in equation (6) are the same, but the uncertainty of asset payoffs given prices and private information is constrained from below ${ }^{12}$

$$
\log \left|\operatorname{Var}\left(\tilde{R} \mid \tilde{Y}_{i}, \tilde{P}\right)\right| \geq \phi \text { where } \phi \in\left(-\infty, \log \left(\sigma_{r, 1}^{2} \sigma_{r, 2}^{2}\right)\right]
$$

Investors are not able to reduce uncertainty about asset payoffs beyond a certain level. $\phi$ is bounded above by $\log \left(\sigma_{r, 1}^{2} \sigma_{r, 2}^{2}\right)$ since this is the uncertainty about asset payoffs if investors do not process any information. If $\phi>-\infty$, then investors are not able to reduce all the uncertainty about asset payoffs and it rules out the perfect information equilibrium since investors are not allowed to choose $\Sigma_{i}=0$.

\footnotetext{
${ }^{12} \mathrm{~A}$ possible way of modelling unlearnable risk in this particular form is by decomposing the error term in the private signal in two components: an unlearnable error term and a learnable error term, $\tilde{\varepsilon}=\tilde{\varepsilon}_{u}+\tilde{\varepsilon}_{l}$, such that investors can only process information through the capacity constraint of the learnable error, $\tilde{\varepsilon}_{l}$.
} 
Proposition 9 There exists imperfect symmetric information equilibria in which investors allocate all of their attention to learn about one linear combination of asset payoffs, $C=\left(1, c_{2}^{*}\right)$ and choose $\Sigma$ to be

$$
\begin{aligned}
& \text { If } \Sigma^{\text {min }}<\Sigma^{L}<\Sigma^{H} \Longrightarrow 3 \text { equilibria }\left\{\begin{array}{c}
\left(c_{2}^{*}, \Sigma^{H}\right) \\
\left(c_{2}^{*}, \Sigma^{L}\right) \\
\left(c_{2}^{*}, \Sigma^{\min }\right)
\end{array}\right. \\
& \text { If } \Sigma^{L}<\Sigma^{\text {min }}<\Sigma^{H} \Longrightarrow \text { unique equilibrium }\left(c_{2}^{*}, \Sigma^{H}\right) \\
& \text { If } \Sigma^{L}<\Sigma^{H}<\Sigma^{\text {min }} \Longrightarrow \text { unique equilibrium }\left(c_{2}^{*}, \Sigma^{\min }\right)
\end{aligned}
$$

where

$$
\begin{aligned}
c_{2}^{*}=\frac{\left(\sigma_{r 2}^{2} \sigma_{z 2}^{2}+\sigma_{r 2}^{2} \bar{z}_{2}^{2}-\sigma_{r 1}^{2} \sigma_{z 1}^{2}-\sigma_{r 1}^{2} \bar{z}_{1}^{2}\right)+\sqrt{\left(\sigma_{r r}^{2} \sigma_{z 2}^{2}+\sigma_{r 2}^{2} \bar{z}_{2}^{2}-\sigma_{r 1}^{2} \sigma_{z 1}^{2}-\sigma_{r 1}^{2} \bar{z}_{1}^{2}\right)^{2}+4 \sigma_{r 1}^{2} \sigma_{r 2}^{2} \bar{z}_{1}^{2} \bar{z}_{2}^{2}}}{2 \sigma_{r 2}^{2} \bar{z}_{1} \bar{z}_{2}} \\
\Sigma^{H}=\frac{\left(\sigma_{r 1}^{2}+c_{2}^{* 2} \sigma_{r 2}^{2}\right)+\sqrt{\left(\sigma_{r 1}^{2}+c_{2}^{* 2} \sigma_{r 2}^{2}\right) \Delta}}{2\left(e^{2 \kappa}-1\right)} \\
\Sigma^{L}=\frac{\left(\sigma_{r 1}^{2}+c_{2}^{* 2} \sigma_{r 2}^{2}\right)-\sqrt{\left(\sigma_{r 1}^{2}+c_{2}^{* 2} \sigma_{r 2}^{2}\right) \Delta}}{2\left(e^{2 \kappa}-1\right)} \\
\Delta=\sigma_{r 1}^{2}+c_{2}^{* 2} \sigma_{r 2}^{2}-4 \rho^{2}\left(e^{2 \kappa}-1\right)^{2}\left(\frac{1}{\sigma_{z 1}^{2}}+\frac{c_{2}^{* 2}}{\sigma_{z 2}^{2}}\right)
\end{aligned}
$$

and $\sum_{i}^{\min }$ is the variance covariance matrix of the error term in the private signal when the unlearnable risk constraint holds with equality

$\Sigma^{\min }=\frac{\left(\sigma_{r 1}^{2}+c_{2}^{* 2} \sigma_{r 2}^{2}\right)+\sqrt{\left(\sigma_{r 1}^{2}+c_{2}^{* 2} \sigma_{r 2}^{2}\right)\left[\sigma_{r 1}^{2}+c_{2}^{* 2} \sigma_{r 2}^{2}+4 \rho^{2}\left(\sigma_{r 1}^{2} \sigma_{r 2}^{2} e^{-\phi}-1\right)\left(\frac{1}{\sigma_{z 1}^{2}}+\frac{c_{2}^{* 2}}{\sigma_{z 2}^{2}}\right)\right]}}{2\left(\sigma_{r 1}^{2} \sigma_{r 2}^{2} e^{-\phi}-1\right)}$ 
as long as the constraint in equation (10) is satisfied.

The perfect information equilibrium does not exist anymore since prices are not allowed to perfectly reveal asset payoff information. Under some conditions, the imperfect information equilibrium is a unique equilibrium. The optimal attention allocation is the same in all three equilibria. If $\Sigma^{\min }<\Sigma^{L}<\Sigma^{H}$, then there are two stable imperfect information equilibria $\left(c_{2}^{*}, \Sigma^{H}\right)$ and $\left(c_{2}^{*}, \Sigma^{\min }\right)$. In the case that $\Sigma^{L}<\Sigma^{\min }<\Sigma^{H}$, then there exists a unique equilibrium $\left(c_{2}^{*}, \Sigma^{H}\right)$. The equilibrium $\left(c_{2}^{*}, \Sigma^{L}\right)$ is not attainable since $\Sigma^{L}$ violates the unlearnable risk constraint. The potential equilibrium $\left(c_{2}^{*}, \Sigma^{\mathrm{min}}\right)$ is not an equilibrium since investors have incentives to deviate from $\Sigma_{i} \in\left(\Sigma^{L}, \Sigma^{H}\right)$ as shown in Proposition 6. If $\Sigma^{L}<\Sigma^{H}<\Sigma^{\min }$, then equilibria $\left(c_{2}^{*}, \Sigma^{H}\right)$ and $\left(c_{2}^{*}, \Sigma^{L}\right)$ violate the unlearnable risk constraint. Therefore, $\left(c_{2}^{*}, \Sigma^{\min }\right)$ is a unique imperfect symmetric equilibrium. Introducing an unlearnable risk constraint rules out the perfect information equilibrium and allows the model to have a unique equilibrium.

\subsubsection{Unlearnable risk through the information processing constraint}

Another way of modelling unlearnable risk is as in Van Nieuwerburgh and Veldkamp (2005a). A fraction $\phi$ of the variance covariance matrix of the asset payoffs given prices,

$\operatorname{Var}(\tilde{R} \mid \tilde{P})$, is not learnable. The objective function in Proposition 2 is the same, but there is a change in the information capacity constraint

$$
\log |(1-\phi) \operatorname{Var}(\tilde{R} \mid \tilde{P})|-\log \left|\operatorname{Var}\left(\tilde{R} \mid \tilde{Y}_{i}, \tilde{P}\right)-\phi \operatorname{Var}(\tilde{R} \mid \tilde{P})\right| \leq 2 \kappa
$$

Investors can only reduce the uncertainty of the learnable component of risk and infinite capacity is required in order to reduce all learnable uncertainty. 
Proposition 10 There exists a stable imperfect information symmetric equilibrium in which investors allocate all their attention to learn about one linear combination of asset payoffs, $C=\left(1, c_{2}^{*}\right)$

$$
c_{2}^{*}=\frac{\left(\sigma_{r 2}^{2} \sigma_{z 2}^{2}+\sigma_{r 2}^{2} \bar{z}_{2}^{2}-\sigma_{r 1}^{2} \sigma_{z 1}^{2}-\sigma_{r 1}^{2} \bar{z}_{1}^{2}\right)+\sqrt{\left(\sigma_{r 2}^{2} \sigma_{z 2}^{2}+\sigma_{r 2}^{2} \bar{z}_{2}^{2}-\sigma_{r 1}^{2} \sigma_{z 1}^{2}-\sigma_{r 1}^{2} \bar{z}_{1}^{2}\right)^{2}+4 \sigma_{r 1}^{2} \sigma_{r 2}^{2} \bar{z}_{1}^{2} \bar{z}_{2}^{2}}}{2 \sigma_{r 2}^{2} \bar{z}_{1} \bar{z}_{2}}
$$

and investors choose $\Sigma$ to be

$\Sigma^{H}=\frac{\left(\sigma_{r 1}^{2}+c_{2}^{* 2} \sigma_{r 2}^{2}\right)+\sqrt{\left(\sigma_{r 1}^{2}+c_{2}^{* 2} \sigma_{r 2}^{2}\right)\left[\sigma_{r 1}^{2}+c_{2}^{* 2} \sigma_{r 2}^{2}-4 \rho^{2}\left(\frac{(1-\phi)\left(e^{2 \kappa}-1\right)}{1+\phi\left(e^{2 \kappa}-1\right)}\right)^{2}\left(\frac{1}{\sigma_{z 1}^{2}}+\frac{c_{2}^{* 2}}{\sigma_{z 2}^{2}}\right)\right]}}{2\left(e^{2 \kappa}-1\right)}$

which exists as long as constraints (10) and

$$
\sigma_{r 1}^{2}+c_{2}^{* 2} \sigma_{r 2}^{2} \geq 4 \rho^{2}\left(\frac{(1-\phi)\left(e^{2 \kappa}-1\right)}{1+\phi\left(e^{2 \kappa}-1\right)}\right)^{2}\left(\frac{1}{\sigma_{z 1}^{2}}+\frac{c_{2}^{* 2}}{\sigma_{z 2}^{2}}\right)
$$

are satisfied.

Unlearnable risk does not change the optimal attention allocation ${ }^{13}$. The model remains the same, but with an extra parameter $\phi$ that restricts the amount of information about the asset payoffs that investors can learn. The higher the unlearnable risk, the higher is the region satisfying the constraint (9), which allows us to have an imperfect information equilibrium. The unlearnable risk parameter shifts the curve in Figure 1 towards the left, which means that the imperfect information equilibrium is attainable in a more broad set of parameters. Therefore, unlearnable risk increases the region of existence of an imperfect information equilibrium.

\footnotetext{
${ }^{13}$ This result would not be true if the fraction of information unlearnable was different in different markets, in other words, if $\phi$ was a matrix with different coefficients.
} 


\section{Proposition 11 There exists a perfect information equilibrium.}

Unlearnable risk does not rule out the perfect information equilibrium. If prices are fully revealing, then investors are able to choose $\Sigma_{i}=0$ without violating the information constraint. If all investors have perfect information, then prices are fully revealing. As a consequence there is nothing to learn and investors never violate the information capacity constraint.

\section{Financial Contagion}

Financial contagion is defined as an increase in volatility and a price drop in one market as a consequence of a financial crisis in another market. I interpret a financial crisis ${ }^{14}$ as an increase in the variance of the asset payoffs. After a stock market is hit by a financial crisis, investors reallocate their attention towards the affected region, which means that the private signal is now providing relatively more information about that risky asset, to the detriment of other stock markets. This effect is called capacity reallocation or attention reallocation and it leads to an increase in the volatility of international capital markets and a collapse of other emerging markets stock prices.

Since risky asset volatilities and prices move in response to the information processed by investors, there exists contagion between stock markets every time there is attention reallocation.

Financial contagion particularly affects emerging markets. Therefore, it seems reasonable to assume that emerging markets are risky enough relative to the risk tolerance and limited capacity to process information of investors ${ }^{15}$ such that the parameter con-

\footnotetext{
${ }^{14}$ There are several causes for financial crises, but a common element in all of them is the increase in the uncertainty of asset payoffs.

${ }^{15}$ From now on, I will use the symmetric equilibrium of the model with no un-learnable risk to explain
} 
straints in equations (9) and (10) are satisfied.

Proposition 12 A financial crisis in one stock market leads to an increase in volatility of other independent stock markets through attention reallocation.

A higher variance of the asset payoffs of a country increases the relative attention allocated to that country, as we have seen in Proposition 8, to the detriment of other risky assets. Since investors are not processing as much information in other stock markets as they used to, there is an endogenous increase in the posterior variance of other emerging market asset payoffs. However, the increase in uncertainty about other emerging markets asset payoffs is smaller the less attention is allocated to these markets. The numerical ${ }^{16}$ example in Figure 2, where the variances of the random variables $\tilde{r}_{1}$, $\tilde{r}_{2}, \tilde{z}_{1}$ and $\tilde{z}_{2}$ are set equal to one, the means equal to three and the risk tolerance equal to one, shows that more attention allocated to the first country (after an increase in $\sigma_{r 1}^{2}$ ) generates a diminishing increase in the posterior volatility of the second region payoff. Intuitively, if an investor is allocating most of her attention to the first market, an increase in the attention allocated to this market will have a small effect in the volatility of the second market. However, if an investor is allocating most of her attention to the second market, an increase in the attention allocated to the first market will have a large effect on the volatility of the second market. Therefore, more attention allocation to one market has an increasing and concave effect on the posterior variance of the other asset payoff.

The numerical example in Figure 3, where the variances of the random variables $\tilde{r}_{1}$, $\tilde{r}_{2}, \tilde{z}_{1}$ and $\tilde{z}_{2}$ are set equal to one, the means equal to three and the risk tolerance equal to one, shows that an increase in the variance of the payoffs in the first stock market leads to financial contagion. In particular, I am interested in looking for contagion in the stable imperfect information symmetric equilibrium with $\left(c_{2}^{*}, \Sigma^{H}\right)$.

${ }^{16}$ The numerical results of this example are robust to changes in the parameters. 
an increase in the asset price volatility of the second market. Investors optimally process more information about the region hit by a financial crisis. The resulting endogenous increase in the posterior volatility of asset payoffs in both regions causes a reduction in the capacity of bearing risks by international investors. Hence, investors liquidate their positions in the risky assets and there is a reduction of market liquidity that leads to an increase in price volatility and a collapse of asset prices in all emerging markets.

Proposition 13 If the two countries are symmetric, a financial crisis in one stock market leads to an increase of the uncertainty and a decrease in the expected prices of the two independent stock markets through attention reallocation.

After a financial crisis hits a region, investors want to pull out from that region because of the increase in riskiness. Hence, stock market prices in this region fall until the diversification motive of the investors plays its role. Even though the region is more risky, investors are interested in diversifying their portfolio and holding the risky asset of the region hit by the crisis. Since this asset became more risky, it is generating more uncertainty in the investor's portfolio and that is why investors are interested in shifting attention to the turbulent region. This is the mechanism that spreads the uncertainty to all financial markets and causes an endogenous increase in the risk premium, a collapse of all the risky asset prices and a flight to quality.

Proposition 14 If the two countries are symmetric, there is a flight to quality when there is a financial crisis.

The model is able to explain the flight to quality after the Asian crisis. The flight to quality is defined as an increase of the wealth allocated to the risk free asset. An increase in the volatility of one stock market is spread to the rest of the international 
capital markets, which causes the collapse of asset prices. Investors always hold the same amount of risky assets because there is a continuum of identical investors that have to hold the net supply. Therefore, investors will allocate a higher amount of wealth to the risk free asset because the increase in riskiness of both stock markets lead to a collapse of financial markets. Hence, there is an increase in bond holdings and in the relative price of the risk free asset, or in other words, there is a flight to quality when there is an increase in the volatility of one stock market.

The model explains short term price comovements among independent assets. After the uncertainty about both stock markets is resolved in the long run, there is no longer any correlation among asset prices. One shortcoming of the paper is that it explains contagion using a static model. Financial contagion is explained using comparative statics.

\section{$5 \quad$ Anticipated vs. Unanticipated Financial Crises}

In the case where the limited information processing capacity, $\kappa$, is interpreted as a long term decision, "fast and furious" contagion only appears in unanticipated financial crises. Kaminsky, Reinhart and Vegh (2003) and Rigobon and Wei (2003) provided empirical evidence that anticipated financial crises such as the devaluation of the real in Brazil on January 1999, the Argentinean default on December 2001 and Turkey's devaluation of the lira on February 2001 were not as contagious as the Mexican, Asian and Russian episodes.

An extension of the model explains the difference between anticipated and unanticipated financial crises as a decision about the limited capacity to process information. If investors anticipate a future financial crisis, they will spend more resources to increase 
the level of limited attention. Therefore, given a higher level of limited information processing capacity, there is less need to reallocate investor's limited attention and financial contagion is less severe. Rigobon and Wei (2003) used the number of articles in newspapers around the world to measure the degree of anticipation of financial crises. They showed that the Argentinean crisis in December of 2001 received attention, in terms of news, more than a year before the devaluation, while there was little news about Thailand before June 1997 even though the country was already under a speculative attack.

Figures 4 to 8 show the evolution of the spreads in Mexico, Russia, Brazil, Turkey and Argentina during their financial crisis period ${ }^{17}$. Figure 4 shows the evolution of the Mexican spreads, which were stable until the peso devaluation in December 21, 1994. In Russia, the spreads took off just when Russia defaulted on its domestic bond debt as shown in Figure 5. These two financial crises are known as contagious episodes. However, as Rigobon and Wei (2003) and Kaminsky, Reinhart and Vegh (2003) suggested, financial crises in Brazil, Turkey and Argentina were not contagious because they were anticipated. Figure 6 shows that Brazilian spreads started rising after the Russian financial turmoil, which indicates that financial turbulence was expected. In Turkey, spreads started rising six months prior the devaluation and flotation of the lira in February 22, 2001 as shown in Figure 7. Argentina's cost of borrowing started rising nine months before the president of Argentina announced his intention of defaulting in December 23, 2001 as seen in Figure 8.

By introducing a strictly convex cost function of limited capacity to process information $c(\kappa)$ in the budget constraint and letting agents choose in an early stage their optimal level of limited information processing capacity, I can show that the degree of

\footnotetext{
${ }^{17}$ Data on spreads for Thailand were not available.
} 
(non)anticipation is crucial for the existence of contagion.

Proposition 15 The optimal level of limited capacity to process information, $\kappa$, is implicitly given by

$$
\frac{2\left[\left(e r_{1}^{2}+Q_{11}\right)+\left(e r_{2}^{2}+Q_{22}\right) c_{2}^{2}+2\left(e r_{1} e r_{2}+Q_{12}\right) c_{2}\right]\left(\alpha \beta-\gamma^{2}\right)}{\alpha+\beta c_{2}^{2}-2 \gamma c_{2}} e^{2 \kappa}-\frac{R}{\rho_{i}} c^{\prime}(\kappa)=0
$$

Proof. See appendix. Expressions for $\alpha, \beta, \gamma, e r_{1}, e r_{2}, Q_{11}, Q_{12}$ and $Q_{22}$ are also in the appendix.

This expression defines an implicit optimal level of information processing capacity, $\kappa$. The results of this section rely on numerical methods since an explicit solution cannot be found. The implicit level of information processing depends on the precision of the error term in the private signal, $\Sigma_{i}^{-1}$. If there is a reduction in the precision of the private signal, investors are willing to purchase more information processing capacity. The higher the uncertainty in the international financial markets, $\sigma_{r 1}^{2}, \sigma_{r 2}^{2}, \sigma_{z 1}^{2}, \sigma_{z 2}^{2}$, the higher the amount of information investors decide to process. An increase in risk aversion has an ambiguous effect on the optimal level of capacity. Investors want to process more information because they dislike risk. On the other hand, risk averse investors allocate less wealth to risky assets, which implies that they do not need as much information as risk tolerant investors. The higher the risk free rate, the lower is the optimal level of limited information processing capacity since the opportunity cost of investing in risky assets has increased.

To have a solution to the optimal choice of limited information processing capacity, $\kappa$, the cost function has to grow fast enough. Otherwise, investors would choose a high limited information processing capacity and they would violate the information constraint in equation (9), which means that the only potential equilibrium is a perfect 
information equilibrium. This type of equilibrium does not exist since investors have the incentive to deviate from it and choose zero capacity because prices would reveal all the information. However, if investors are not processing information about the asset payoffs, then prices are not informative at all. This is an information collection paradox as in Grossman and Stiglitz (1980).

If the optimal decision of $\kappa$ is interpreted as a long term decision, then the model is able to distinguish anticipated versus unanticipated crises. In an anticipated crisis, investors will foresee problems in the future and they will allocate more resources to information processing. This will help decrease financial contagion among regions. However, in unanticipated crises, when investors realize that there is a financial crisis in the stock market, $\kappa$ is already chosen and it is then, when financial contagion hits the international financial markets.

To illustrate that the degree of (non)anticipation is crucial for the existence of contagion, I provide numerical results for the case where the variances of the random variables $\tilde{r}_{1}, \tilde{r}_{1}, \tilde{z}_{1}$ and $\tilde{z}_{2}$ are set equal to one and the means equal to three ${ }^{18}$. The risk tolerance parameter is set equal to one and the cost function ${ }^{19}$ is $c(\kappa)=$ $(\exp (4 \kappa)-1)+(\exp (-4 \kappa)-1)$.

As we can see in Figure 9, the higher the variance in one of the risky assets, the more attention investors want to allocate to analyze the international financial markets. Figure 10 shows the effect on expected prices of an anticipated increase in the volatility of the first stock market. If a financial crisis is anticipated, then more information processing capacity is acquired as we see in Figure 9. Figure 10 shows that the expected price of the first asset is decreasing with its volatility. However, the expected price of

\footnotetext{
${ }^{18}$ The aim of the model is to provide qualitative results in a very simple model. I am not trying to calibrate the model to match reality.

${ }^{19}$ This particular cost function is only introduced for simplicity since information processing capacity always appears in the model with an exponential term.
} 
the second asset is increasing with an increase in variance of the first stock market. In this case, the increase in information processing capacity dominates the attention reallocation effect since there is less need to reallocate investors' limited attention and financial contagion does not occur. The results in these two figures are robust to changes in all of the parameters of the model.

Figure 11 shows the effect on expected prices of an unanticipated financial crisis that is when the limited capacity to process information remains constant ${ }^{20}$. If there is an unanticipated increase in the volatility of the first stock market, then financial contagion occurs as shown in Section 4.

\section{Empirical Analysis}

This section shows evidence of financial contagion through attention reallocation. In Section 4, I showed that in a model with two independent risky assets and a risk free asset, an increase in the volatility of one region causes an endogenous increase in the volatility of another independent region through attention reallocation.

\subsection{Data}

The data are a panel of daily observations of the total return index for Brazil, Chile, Argentina and Thailand and the number of news articles in the Financial Times about each of these countries between January $1^{\text {st }}, 1997$, and June $30^{\text {th }}, 1998$. Table 1 contains descriptive statistics for the number of news articles, the total return index and the total return index volatility of each country.

The return index is from the Datastream Global Index. The return index represents

\footnotetext{
${ }^{20}$ The limited capacity is held constant at the optimal level when $\sigma_{r, 1}^{2}=1$.
} 
the theoretical aggregate growth in value of the constituents of the index. The index constituents are deemed to return an aggregate daily dividend which is included as an incremental amount to the daily change in price index. The total return index ${ }^{21}$, which measures a country's market capitalization plus cash dividends, corresponds to the payoffs of the risky assets in the model.

The return index volatility is measured as the absolute percent change in the total return index that is calculated as the absolute value ${ }^{22}$ of $\left[\log \left(R_{t}\right)-\log \left(R_{t-1}\right)\right]$ as in Kaminsky and Schmukler (1999).

Brazil, Chile and Argentina ${ }^{23}$ are the countries selected to study financial contagion from Thailand because they are countries from a different region with weak economic links. For instance, total Brazilian, Chilean and Argentinean trade ${ }^{24}$ with Thailand represented less than $0.5 \%$ of their GDP ${ }^{25}$ in 1996 as we can see in Table 2 . Therefore, we can consider Thailand and Brazil as two countries with independent economic linkages.

The news articles in the Financial Times about Thailand, Brazil and Chile are taken from the Lexis Nexis Database. This variable consists of the number of daily news articles in the Financial Times with the name or adjective of the country in the title or lead paragraph of the article. The news articles in the Financial Times are used as a proxy for attention allocation. The Financial Times is assumed to match how the representative international investor decides how much attention is allocated to each country. In other words, I assume that news stories in the Financial Times are driven by investors' demand for information and investors process information about

\footnotetext{
${ }^{21}$ I use the return Index in US dollars since this is the standard way of studying contagion in the literature.

${ }^{22}$ The results are robust to other measures of volatility as the squared root of the percentage change in the total return index.

${ }^{23}$ I consider all these countries as emerging markets whose stock market volatility is close enough to the Thai stock market volatility such that I can use the symmetric country result of Proposition 13.

${ }^{24}$ Total Trade is measured as total exports plus total imports in US dollars.

${ }^{25}$ Nominal GDP is measured in US dollars.
} 
international financial markets by reading the Financial Times. The higher the number of news articles about a country, the more attention is allocated to that country.

The period of time examined is from January 1997 to June 1998. This is the period selected by Nouriel Roubini in the "Chronology of the Asian Currency Crisis and its Global Contagion". The start of the East Asian crisis is considered to be on July $2^{\text {nd }}$, 1997, with the devaluation of the Thai Baht, although there were speculative attacks on the currency before that date. There was financial turbulence until June 1998 which is considered the end of the Asian financial turmoil. Since there is evidence of speculative attacks on Thailand, I assume that investors were updating their beliefs about the volatility of the asset payoffs in Thailand ${ }^{26}$. The purpose of this section is to study the effect of an increase in the volatility of the Thai stock market in the volatility of the Brazilian, Chilean and Argentinean stock markets through attention reallocation.

The time difference between Thailand, London ${ }^{27}$ and Latin American countries is a key element to understand this empirical section. The time zone of Thailand is GMT +07:00, London GMT, Brazil and Argentina GMT -03:00 and Chile GMT -04:00. When the Thai stock market opens on a particular date, the news articles of the Financial Times in London are already written. Hence, current volatility in Thailand appears as news stories in the Financial Times the following day. When Latin American stock markets open on a particular date, the Asian stock markets are closing. Hence, today's Latin American stock market volatility does not have any effect in today's Asian stock

\footnotetext{
${ }^{26}$ In terms of the model, investors are updating their beliefs about the first stock market by increasing $\sigma_{r 1}^{2}$. The model predicts financial contagion by doing comparative statics on the variance of the asset payoffs.

${ }^{27}$ The time difference with London is important because it is the place where the Financial Times is written.
} 
market volatility.

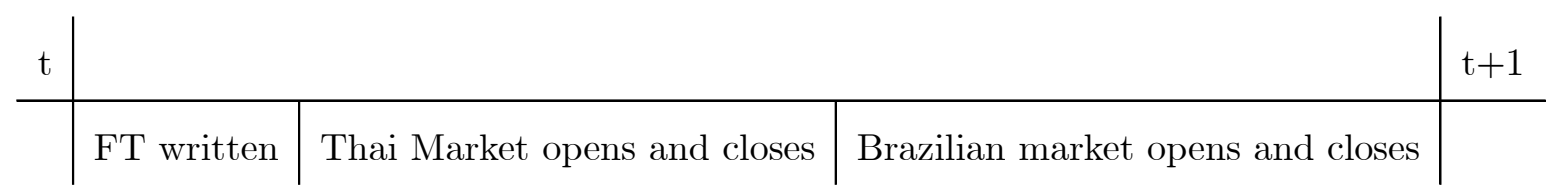

\subsection{Financial Contagion and Attention Allocation}

The model predicts that an increase in the volatility of Thailand should lead investors to allocate more attention to the Thai stock market, which implies that the number of stories about Thailand in the Financial Times should increase. The model also predicts that if more attention is allocated to Thailand, then the volatility of the Brazilian stock market should increase. Thus, the data should show that if the number of news articles in the Financial Times about Thailand increases, then there is an increase in uncertainty in the Brazilian market.

Table 3 uses the data to estimate the relationship between the volatility of the Thai stock market and the number of news about Thailand ${ }^{28}$. The first column shows that the number of news stories about Thailand is positively and significantly correlated with the volatility in the Thai market. This implies that the more uncertainty about a country, the higher the attention allocated to that country. The number of news articles is evaluated one period ahead since the attention allocated to Thailand appears in the Financial Times as more news stories the next day. The results in Table 3 are robust to the introduction of two lags for the Thai news variable ${ }^{29}$ as shown in the second column of the same Table. This regression also shows that volatility in the Thai stock market

\footnotetext{
${ }^{28}$ The model does not focus on absolute attention, but relative attention. However, there is only need to consider news in the Financial Times about Thailand. The Financial Times has a format where an approximately constant amount of news can be published. Therefore, the more news about Thailand, the more attention is allocated to Thailand relative to the rest of the world.

${ }^{29}$ The number of lags for the Thai news variable is chosen using the Schwartz information criterion, also called the Bayesian information criterion.
} 
Granger causes more news articles about Thailand the next day. The third, fourth and fifth columns also show that an increase in the Thai volatility is consistent with an increasing and concave effect on the number of news articles about Thailand ${ }^{30}$.

Similar results to Table 3 are found by Veldkamp (2004), where she shows that asset payoff volatility generates demand for news, which in terms of attention allocation means that an increase in the variance of the asset payoffs causes an increase of attention allocated to that stock market. However, she did a pooled regression with weekly data on 23 emerging stock markets between 1989 and 2002 and a weekly count of the number of news articles from the Financial Times that contain the name of the country or the adjective form of that name in the title or lead paragraph.

The model also predicts that if more attention is allocated to Thailand, then the volatility of the Brazilian stock market should increase. Table 4 shows the relationship between the volatility in Brazil and the number of news articles about Thailand. The coefficients imply that an increase in news articles about Thailand causes a statistically significant increase in the volatility of Brazil. Recall that the model predicts an increasing and concave effect in the number of news articles about Thailand over the Brazilian volatility as shown in Figure 2. Hence, a quadratic term for the variable Thai news is introduced in the second column of Table 4. The linear term of this variable is still positive, increases and becomes statistically more significant, while the quadratic term is negative and statistically significant, which seems to support the result that the attention allocated to Thailand has an increasing and concave effect on the Brazilian volatility. This result is robust to other increasing and concave transformations of the variable Thai news as shown in the third, fourth and fifth column. The coefficients indicate that twenty news stories about Thailand in the Financial Times generates a

\footnotetext{
${ }^{30}$ These results are robust to different measures of volatility as the quadratic percentage change in the total return index. These tables are available upon request.
} 
daily change of $1.4 \%$ in the total return index. However, in this Table, the number of news in the Financial Times about Thailand could be picking up other effects such as common shocks or other transmission mechanisms of financial crisis.

Tables 5 and 6 also show the relationship between the volatility in Brazil and the number of news articles about Thailand, but introducing the following control variables: the Federal Funds rate target, Treasury Bills and Treasury Bonds of the U.S. to control for common shocks; a dummy variable called "HK Dummy" to distinguish the period after October $17^{\text {th }}, 1997$, where there was a change in the level of international stock markets because of the Hang Seng collapse; the current stock market volatility of Thailand and Asia ${ }^{31}$ to pick up the effect of global shocks; past volatility in Thailand and $\mathrm{Asia}^{32}$ to isolate the effect that attention allocation has in the volatility of Latin American countries; and three lags to the volatility of Brazil ${ }^{33}$ to control for regional shocks.

The coefficients of the variable Thai news in Tables 5 and 6 are still statistically significant and remain qualitatively and quantitatively the same as the coefficients in Table 4. These two Tables support the increasing and concave effect of news articles about Thailand over the Brazilian volatility and show that the Thai news articles Granger cause the volatility in Brazil. The coefficients indicate that twenty news stories about Thailand in the Financial Times generates a daily change of $1.1 \%$ in the total return index. This is only part of the attention reallocation effect. There is another part of the attention reallocation effect that cannot be distinguished from other transmission mechanisms. The current and past Thai and Asian volatilities are picking up the direct

\footnotetext{
${ }^{31}$ The stock market volatility of Asia includes the following stock markets: China, Hong Kong, India, Indonesia, Japan, Malaysia, Philippines, Singapore, South Korea, Taiwan and Thailand.

${ }^{32}$ The empirical literature testing for contagion usually focuses on the coefficient of current and past Asian volatility to determine if there was contagion to Latin America.

${ }^{33}$ The number of lags for a country's stock market volatility is chosen using the Schwartz information criterion, also called the Bayesian information criterion.
} 
effect of contagion to Brazil from all the potential transmission mechanisms. These coefficients do not seem to point out real links as the main channel of contagion as explained by Kaminsky, Reinhart and Vegh (1999), but they are providing evidence of a common shock or financial contagion through several indistinguishable transmission channels.

Tables 7, 8 and 9 provide support for financial contagion from Thailand to Chile through attention reallocation. These Tables show that the Thai news articles also have an increasing and concave effect on the Chilean volatility. However, the isolated effect of financial contagion through attention reallocation is not significant for Argentina as shown in Table 10. The coefficients of current and past volatility in Asia are statistically significant, which seems to indicate that there was financial contagion, but it is not possible to distinguish what is the transmission mechanism that is causing it. Hence, a nonsignificant coefficient in the Thai news variable does not necessarily imply that attention reallocation had no effect on Argentina.

The empirical results are also robust to a change in the measure of volatility. Table 11 shows financial contagion to Brazil through attention reallocation using as a measure of volatility the squared change of stock market returns $\left[\log \left(R_{t}\right)-\log \left(R_{t-1}\right)\right]^{2}$.

\section{Conclusion}

This paper presents a rational expectations model of asset prices with information processing constraints and explains the transmission of financial crises as a change in the attention allocation of investors over short periods of time.

Devaluations and defaults have triggered "fast and furious" financial contagion episodes in the last decade. When a financial crisis hits a country, the amount of daily news, rumors and concerns increases dramatically. I model the process of attention allocation 
that underlies portfolio investment in international markets. Investors optimally allocate more attention to the region hit by a financial crisis, to the detriment of other regions. The resulting endogenous increase in the posterior volatility of asset payoffs causes a reduction in the capacity of bearing risks by international investors and an increase in the risk premium on all stock markets. Hence, investors liquidate their positions in the risky assets and there is a reduction of market liquidity that leads to an increase in price volatility and a collapse of asset prices in all emerging markets.

Financial contagion between two independent international stock markets arises even in the absence of correlated information shocks, correlated liquidity shocks, direct or indirect macroeconomic links and borrowing constraints, provided there is attention reallocation.

Empirical evidence for the East Asian financial crisis supports attention reallocation as a transmission mechanism of financial crises. The number of news stories about Thailand in the Financial Times is used as a proxy for the attention allocated to the Thai stock market. The data show that the increase in uncertainty about Thailand in 1997 generated an increase in the volatility of the Latin American stock markets through attention reallocation of international investors.

In the case where the limited information processing capacity is interpreted as a long term decision, an extension of the model allows one to distinguish between anticipated and unanticipated crises. This is the first theoretical model, to my knowledge, that points towards the degree of (non)anticipation of a financial crisis as the explanation of why some crises cause severe financial contagion and why others do not. If a financial crisis suddenly hits a country, investors are taken by surprise and there exists financial contagion through attention reallocation. However, if financial turbulence is expected, then more information processing capacity is acquired and less attention needs to be 
reallocated when the financial crisis arises.

This extension provides an explanation for the existence of international credit rating agencies. The effects of financial contagion are less severe when financial crises are anticipated. Therefore, credit ratings by international agencies alert investors of possible future financial turbulence and help reduce the effects of financial contagion.

Finally, this paper represents a step forward towards the introduction of rational inattention into a general equilibrium finance model. However, several assumptions should be relaxed in order to have a general equilibrium model with rationally inattentive agents. The model assumes that investors have Gaussian uncertainty about the random variable of interest, in this case asset payoffs, ex ante and ex post. Sims (2005) presents a methodology to find the nature of the ex post uncertainty about the random variable of interest. Another assumption of the model is that rationally inattentive agents are able to freely observe prices, which means that investors have an unbounded capacity to process information about prices. They are also unable to process information about the random asset supply, so the cost of processing information about the noisy asset supply is infinite. A potential extension of the model is to relax these two assumptions by having investors who observe prices with a measurement error. Then, the noisy asset supply assumption can be dropped since prices are unobservable. In this case, investors will not process information about prices or asset payoffs individually, but the variable of interest for investors will be the asset excess returns. Hence, investors, when deciding their asset holdings, will not pay attention to the price, but they will process information about the asset excess returns. 


\section{Appendix}

Proof of Proposition 1. The objective function in the third period is a standard mean variance objective function. A closed form solution of a REE can be derived using these five steps, following Admati (1985) and Brunnermeier (2001):

1. Price conjecture

$$
\tilde{P}=A_{0}+A_{1} \tilde{R}-A_{2} \tilde{Z}
$$

2. Derive posterior beliefs

$$
E\left[\tilde{R} \mid \tilde{Y}_{i}, \tilde{P}\right]=B_{0 i}+B_{1 i} \tilde{Y}_{i}+B_{2 i} \tilde{P}
$$

3. Derive optimal demand

$$
X_{i}\left(\tilde{Y}_{i}, \tilde{P}\right)=\rho_{i} \operatorname{Var}\left[\tilde{R} \mid \tilde{Y}_{i}, \tilde{P}\right]^{-1}\left(B_{0 i}+B_{1 i} \tilde{Y}_{i}+\left(B_{2 i}-R I\right) \tilde{P}\right)
$$

4. Impose the market clearing conditions for all markets and compute the endogenous market clearing price variables.

5. Impose rational expectations, that is, the conjectured price function has to coincide with the actual price function.

Equilibrium prices have the following form

$$
\tilde{P}=A_{0}+A_{1} \tilde{R}-A_{2} \tilde{Z} \text {, with } A_{2} \text { nonsingular }
$$


where

$$
\begin{aligned}
& A_{0}=\frac{\bar{\rho}}{R}\left(\bar{\rho} \Sigma_{R}^{-1}+\bar{\rho} \Pi \Sigma_{Z}^{-1} \Pi+\Pi\right)^{-1}\left(\Sigma_{R}^{-1} \bar{R}+\Pi \Sigma_{Z}^{-1} \bar{Z}\right) \\
& A_{1}=\frac{1}{R}\left(\bar{\rho} \Sigma_{R}^{-1}+\bar{\rho} \Pi \Sigma_{Z}^{-1} \Pi+\Pi\right)^{-1}\left(\Pi+\bar{\rho} \Pi \Sigma_{Z}^{-1} \Pi\right) \\
& A_{2}=\frac{1}{R}\left(\bar{\rho} \Sigma_{R}^{-1}+\bar{\rho} \Pi \Sigma_{Z}^{-1} \Pi+\Pi\right)^{-1}\left(I+\bar{\rho} \Pi \Sigma_{Z}^{-1}\right)
\end{aligned}
$$

where $\bar{\rho}=\int_{0}^{1} \rho_{i} d i$. Following Admati, I defined $\Pi$ as the average precision matrix of the signals weighted by the risk tolerance coefficient.

$$
\Pi=\left[\int_{0}^{1} \rho_{i} C_{i}^{\prime} \Sigma_{i}^{-1} C_{i} d i\right]
$$

Intuitively, $\Pi$ contains the average stock market information processed by the investors. The conditional distribution of $\tilde{R}$ given a private signal $\tilde{Y}_{i}$ and the equilibrium price vector $\tilde{P}$ is a multivariate normal with expectation

$$
E\left[\tilde{R} \mid \tilde{Y}_{i}, \tilde{P}\right]=B_{0 i}+B_{1 i} \tilde{Y}_{i}+B_{2 i} \tilde{P}
$$

where

$$
\begin{aligned}
B_{1 i} & =V_{i} C_{i}^{\prime} \Sigma_{i}^{-1} \\
B_{2 i} & =V_{i} \Pi \Sigma_{Z}^{-1} A_{2}^{-1} \\
B_{0 i} & =V_{i}\left(I+\bar{\rho} \Pi \Sigma_{Z}^{-1}\right)^{-1}\left(\Sigma_{R}^{-1} \bar{R}+\Pi \Sigma_{Z}^{-1} \bar{Z}\right)
\end{aligned}
$$

and variance-covariance matrix

$$
V_{i}=\operatorname{Var}\left[\tilde{R} \mid \tilde{Y}_{i}, \tilde{P}\right]=\left(\Sigma_{R}^{-1}+\Pi \Sigma_{Z}^{-1} \Pi+C_{i}^{\prime} \Sigma_{i}^{-1} C_{i}\right)^{-1}
$$


The optimal asset holdings by an investor $i$, who observes the state of the world with a measurement error $\tilde{Y}_{i}$ and the equilibrium price vector $\tilde{P}$, are given by

$$
X_{i}\left(\tilde{Y}_{i}, \tilde{P}\right)=G_{0 i}+G_{1 i} \tilde{Y}_{i}-G_{2 i} \tilde{P}
$$

where

$$
\begin{aligned}
G_{1 i} & =\rho_{i} C_{i}^{\prime} \Sigma_{i}^{-1} \\
G_{2 i} & =\rho_{i} R\left[\left(I+\bar{\rho} \Pi \Sigma_{Z}^{-1}\right)^{-1} \Sigma_{R}^{-1}+C_{i}^{\prime} \Sigma_{i}^{-1} C_{i}\right] \\
G_{0 i} & =\rho_{i} G_{0}=\rho_{i}\left(I+\bar{\rho} \Pi \Sigma_{Z}^{-1}\right)^{-1}\left(\Sigma_{R}^{-1} \bar{R}+\Pi \Sigma_{Z}^{-1} \bar{Z}\right)
\end{aligned}
$$

For a more detailed solution of the Proposition 1 see Admati (1985).

Proof of Proposition 2. First, rewrite the objective function. Then, proceed with the optimal attention allocation.

$$
E U_{i}=E\left[E\left[W_{i}^{\prime} \mid \tilde{Y}_{i}, \tilde{P}\right]-\frac{1}{2 \rho_{i}} \operatorname{Var}\left[W_{i}^{\prime} \mid \tilde{Y}_{i}, \tilde{P}\right]\right]
$$

where

$E\left[W_{i}^{\prime} \mid \tilde{Y}_{i}, \tilde{P}\right]=W_{i 0} R+\rho_{i}\left[E\left[\tilde{R} \mid \tilde{Y}_{i}, \tilde{P}\right]-R \tilde{P}\right]^{\prime} \operatorname{Var}\left[\tilde{R} \mid \tilde{Y}_{i}, \tilde{P}\right]^{-1}\left[E\left[\tilde{R} \mid \tilde{Y}_{i}, \tilde{P}\right]-R \tilde{P}\right]$

and

$$
\operatorname{Var}\left[W_{i}^{\prime} \mid \tilde{Y}_{i}, \tilde{P}\right]=\rho_{i}^{2}\left[E\left[\tilde{R} \mid \tilde{Y}_{i}, \tilde{P}\right]-R \tilde{P}\right]^{\prime} \operatorname{Var}\left[\tilde{R} \mid \tilde{Y}_{i}, \tilde{P}\right]^{-1}\left[E\left[\tilde{R} \mid \tilde{Y}_{i}, \tilde{P}\right]-R \tilde{P}\right]
$$


The objective function becomes

$$
=E\left[\frac{1}{2} \rho_{i}\left[E\left[\tilde{R} \mid \tilde{Y}_{i}, \tilde{P}\right]-R \tilde{P}\right]^{\prime} V_{i}^{-1}\left[E\left[\tilde{R} \mid \tilde{Y}_{i}, \tilde{P}\right]-R \tilde{P}\right]+R W_{0, i}\right]
$$

Note that

$$
\begin{aligned}
E R & =E\left[E\left[\tilde{R} \mid \tilde{Y}_{i}, \tilde{P}\right]-R \tilde{P}\right]=\left(I-R A_{1}\right) \bar{R}-R A_{0}+R A_{2} \bar{Z} \\
& =\left(\bar{\rho} \Sigma_{R}^{-1}+\bar{\rho} \Pi \Sigma_{Z}^{-1} \Pi+\Pi\right)^{-1} \bar{Z}
\end{aligned}
$$

where $E R=\left(e r_{1}, e r_{2}\right)^{\prime}$ and

$$
\begin{aligned}
Q & =\operatorname{Var}\left[E\left[\tilde{R} \mid \tilde{Y}_{i}, \tilde{P}\right]-R \tilde{P}\right]+V_{i}=\Sigma_{R}+R^{2} A_{1} \Sigma_{R} A_{1}^{\prime}+R^{2} A_{2} \Sigma_{Z} A_{2}^{\prime}-R A_{1} \Sigma_{R}-R \Sigma_{R} A_{1}^{\prime} \\
& =\left(\begin{array}{cc}
Q_{11} & Q_{12} \\
Q_{12} & Q_{22}
\end{array}\right)
\end{aligned}
$$

Let $x=\left(x_{1}, x_{2}, \ldots, x_{n}\right)^{\prime} \sim N(\mu, V)$. Define the quadratic form $q=x^{\prime} A x$, then the expected value of $q$ is $E(q)=\operatorname{tr}[A V]+\mu^{\prime} A \mu$. Therefore, the objective function is given by

$$
\rho_{i} \operatorname{Tr}\left(\frac{1}{2} V_{i}^{-1} Q\right)+\frac{1}{2} \rho_{i}\left[E\left[\tilde{R} \mid \tilde{Y}_{i}, \tilde{P}\right]-R \tilde{P}\right]^{\prime} V_{i}^{-1}\left[E\left[\tilde{R} \mid \tilde{Y}_{i}, \tilde{P}\right]-R \tilde{P}\right]+R W_{0, i}
$$

Proof of Proposition 3. For any economy in which agents receive signals of the form $\tilde{Y}_{i}=C_{i} \tilde{R}+\tilde{\varepsilon}_{i}$, there exists an economy identical to the original in which investors receive private signals $\tilde{Y}_{i}^{*}=\mu \tilde{Y}_{i}=\mu C_{i} \tilde{R}+\mu \tilde{\varepsilon}_{i}$ that has an equilibrium which 
is indistinguishable from the equilibrium in the original economy and that satisfies the information capacity constraint as well. First, check that the equilibrium is indistinguishable between both economies. There is enough to prove that $\Pi=\Pi^{*}$

$$
\Pi=\int_{0}^{1} \rho_{i} C_{i}^{\prime} \Sigma_{i}^{-1} C_{i} d i=\int_{0}^{1} \rho_{i} \mu C_{i}^{\prime}\left(\mu^{2} \Sigma_{i}\right)^{-1} \mu C_{i} d i=\int_{0}^{1} \rho_{i} C_{i}^{* \prime}\left(\Sigma_{i}^{*}\right)^{-1} C_{i}^{*} d i=\Pi^{*}
$$

More details are provided in Admati (1985). Second, let's check that the new private signal satisfies the information capacity constraint. A nice property of Mutual Information is that it is invariant to any linear combination of the random variables, which implies

$$
I(X ; Y)=I(X ; \mu Y)=H(X)-H(X \mid Y) \leq \kappa
$$

Therefore, we need to introduce a constraint on $C_{i}$ in order to avoid the existence of indistinguishable equilibria. The relative weight of the linear combination in the private signal is what matters for the investor. We can normalize one element of each row vector of $C_{i}$. For any optimal linear combination of asset payoffs, $C_{i}^{*}$, which is

$$
C_{i}^{*}=\left(\begin{array}{cc}
1 & c_{2 i} \\
c_{1 i} & 1
\end{array}\right)
$$

let investors choose the optimal variance covariance matrix of the error in the private signal, $\Sigma_{i}$. The variance covariance matrix can be decomposed as follow

$$
\Sigma_{i}=P \Lambda P^{\prime}
$$

where $\Lambda$ is a diagonal matrix and $P^{\prime}=P^{-1}$. For every non-diagonal $\Sigma_{i}$, there exists an 
indistinguishable equilibrium where investors receive a private signal $\tilde{Y}_{i}^{*}$ given by

$$
\tilde{Y}_{i}^{*}=P^{-1} \tilde{Y}_{i}=P^{-1} C_{i} \tilde{R}+P^{-1} \tilde{\varepsilon}_{i}=C_{i}^{*} \tilde{R}+\tilde{\varepsilon}_{i}^{*}
$$

where $\operatorname{var}\left(\tilde{\varepsilon}_{i}^{*}\right)=\Lambda$ is a diagonal matrix. Therefore, without loss of generality for a given optimal matrix $C_{i}$, we can let investors choose a diagonal variance covariance matrix of the error term in the private signal

$$
\Sigma_{i}=\left(\begin{array}{cc}
\sigma_{i 1} & 0 \\
0 & \sigma_{i 2}
\end{array}\right)
$$

Agents maximize their objective function

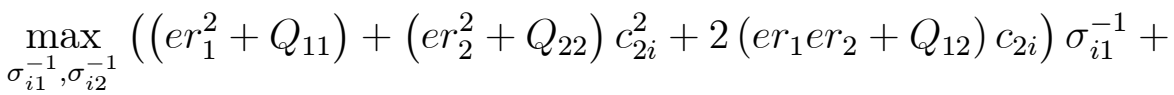

$$
\begin{aligned}
& +\left(\left(e r_{1}^{2}+Q_{11}\right) c_{1 i}^{2}+\left(e r_{2}^{2}+Q_{22}\right)+2\left(e r_{1} e r_{2}+Q_{12}\right) c_{1 i}\right) \sigma_{i 2}^{-1}+\text { constant }
\end{aligned}
$$

subject to the information constraint

$\left(\alpha+\beta c_{2 i}^{2}-2 \gamma c_{2 i}\right) \sigma_{i 1}^{-1}+\left(\alpha c_{1 i}^{2}+\beta-2 \gamma c_{1 i}\right) \sigma_{i 2}^{-1}+\left(\alpha \beta-\gamma^{2}\right)\left(1-c_{1 i} c_{2 i}\right)^{2} \sigma_{i 1}^{-1} \sigma_{i 2}^{-1}=\left(\alpha \beta-\gamma^{2}\right)\left(e^{2 \kappa}-1\right)$

where

$$
\begin{aligned}
& e r_{1}=\frac{\left(\rho \alpha+\pi_{22}\right) \bar{z}_{1}-\left(\rho \gamma+\pi_{12}\right) \bar{z}_{2}}{\left(\rho \beta+\pi_{11}\right)\left(\rho \alpha+\pi_{22}\right)-\left(\rho \gamma+\pi_{12}\right)^{2}} \quad e r_{2}=\frac{\left(\rho \beta+\pi_{11}\right) \bar{z}_{2}-\left(\rho \gamma+\pi_{12}\right) \bar{z}_{1}}{\left(\rho \beta+\pi_{11}\right)\left(\rho \alpha+\pi_{22}\right)-\left(\rho \gamma+\pi_{12}\right)^{2}} \\
& \alpha=\frac{1}{\sigma_{r 2}^{2}}+\frac{\pi_{12}^{2}}{\sigma_{z 1}^{2}}+\frac{\pi_{22}^{2}}{\sigma_{z 2}^{2}} \quad \beta=\frac{1}{\sigma_{r 1}^{2}}+\frac{\pi_{11}^{2}}{\sigma_{z 1}^{2}}+\frac{\pi_{12}^{2}}{\sigma_{z 2}^{2}} \quad \gamma=\frac{\pi_{11} \pi_{12}}{\sigma_{z 1}^{2}}+\frac{\pi_{12} \pi_{22}}{\sigma_{z 2}^{2}} \\
& \pi_{11}=\rho \Sigma_{i}^{-1} \quad \pi_{12}=\rho \Sigma_{i}^{-1} c_{2}^{*}=\pi_{11} c_{2}^{*} \quad \pi_{22}=\rho \Sigma_{i}^{-1} c_{2}^{* 2}=\pi_{11} c_{2}^{* 2}
\end{aligned}
$$

The investor when optimizing takes as given $e r_{1}, e r_{2}, \alpha, \beta, \gamma, \pi_{11}, \pi_{12}$ and $\pi_{22}$. Due to the 
linearity of the objective function in the precision of each private signal and the form of the information constraint, the maximum is a corner solution. Therefore, investors want to allocate all their attention in only one linear combination of asset payoffs.

Proof of Proposition 4. The objective function in the second period is given by

$$
\max _{C_{i}, \Sigma_{i}^{-1}} \operatorname{Tr}\left(V_{i}^{-1} Q\right)+E R^{\prime} V_{i}^{-1} E R
$$

subject to the information capacity constraint

$$
\ln |\operatorname{Var}(\tilde{R} \mid \tilde{P})|-\ln \left|\operatorname{Var}\left(\tilde{R} \mid \tilde{Y}_{i}, \tilde{P}\right)\right| \leq 2 \kappa
$$

which can be also written as

$$
\left|I+\left(\Sigma_{R}^{-1}+\Pi \Sigma_{Z}^{-1} \Pi\right)^{-1} C_{i}^{\prime} \Sigma_{i}^{-1} C_{i}\right| \leq \exp (2 \kappa)
$$

The precision of the error of the private signal can be obtained rearranging the information capacity constraint

$$
\Sigma_{i}^{-1}=\frac{\left(e^{2 \kappa}-1\right)\left(\alpha \beta-\gamma^{2}\right)}{\alpha c_{1 i}^{2}+\beta c_{2 i}^{2}-2 \gamma c_{1 i} c_{2 i}}
$$

where $\alpha, \beta$ and $\gamma$ are given in (13) and $\pi_{11}, \pi_{12}$ and $\pi_{22}$ are given in (14). Normalizing $c_{1 i}=1$ and substituting the information constraint in the objective function, the optimization problem becomes

$$
\max _{c_{2 i}} \frac{\left[\left(e r_{1}^{2}+Q_{11}\right)+\left(e r_{2}^{2}+Q_{22}\right) c_{2 i}^{2}+2\left(e r_{1} e r_{2}+Q_{12}\right) c_{2 i}\right]\left(e^{2 \kappa}-1\right)\left(\alpha \beta-\gamma^{2}\right)}{\alpha+\beta c_{2 i}^{2}-2 \gamma c_{2 i}}
$$

where $\alpha, \beta$ and $\gamma$ are given in (13), $\pi_{11}, \pi_{12}$ and $\pi_{22}$ are given in (14) and $e r_{1}$ and $e r_{2}$ 
are given in (12). The investor when optimizing takes as given $e r_{1}, e r_{2}, \alpha, \beta, \gamma, \pi_{11}, \pi_{12}$ and $\pi_{22}$. The optimal $c_{2 i}$ is given by solving this quadratic equation

$$
\begin{gathered}
-\left(\beta\left(e r_{1} e r_{2}+Q_{12}\right)+\gamma\left(e r_{2}^{2}+Q_{22}\right)\right) c_{2 i}^{2}-\left(\beta\left(e r_{1}^{2}+Q_{11}\right)-\alpha\left(e r_{2}^{2}+Q_{22}\right)\right) c_{2 i}+ \\
+\left(\alpha\left(e r_{1} e r_{2}+Q_{12}\right)+\gamma\left(e r_{1}^{2}+Q_{11}\right)\right)=0
\end{gathered}
$$

where $\Sigma_{i}$ is given by equation (15). This is the reaction function where investors take as given the aggregate variables of the economy. Since the investor has an infinitesimal measure, her decision does not have any effect on the price. The optimal $c_{2 i}$ is given by

$$
\begin{aligned}
& c_{2 i}^{*}=\frac{\left[\alpha\left(e r_{2}^{2}+Q_{22}\right)-\beta\left(e r_{1}^{2}+Q_{11}\right)\right]}{2\left[\beta\left(e r_{1} e r_{2}+Q_{12}\right)+\gamma\left(e r_{2}^{2}+Q_{22}\right)\right]}+ \\
& +\frac{\sqrt{\left[\alpha\left(e r_{2}^{2}+Q_{22}\right)-\beta\left(e r_{1}^{2}+Q_{11}\right)\right]^{2}+4\left[\beta\left(e r_{1} e r_{2}+Q_{12}\right)+\gamma\left(e r_{2}^{2}+Q_{22}\right)\right]\left[\alpha\left(e r_{1} e r_{2}+Q_{12}\right)+\gamma\left(e r_{1}^{2}+Q_{11}\right)\right]}}{2\left[\beta\left(e r_{1} e r_{2}+Q_{12}\right)+\gamma\left(e r_{2}^{2}+Q_{22}\right)\right]}
\end{aligned}
$$

The second order conditions are given by

$$
-2\left[\beta\left(e r_{1} e r_{2}+Q_{12}\right)+\gamma\left(e r_{2}^{2}+Q_{22}\right)\right] c_{2 i}^{*}-\alpha\left(e r_{2}^{2}+Q_{22}\right)+\beta\left(e r_{1}^{2}+Q_{11}\right)<0
$$

The other solution to the second order equation is always a minimum. The symmetric equilibrium is given by the optimal $c_{2 i}$ which is consistent with all investors choosing the same $c_{2 i}$. By substituting the values of $e r_{1}, e r_{2}, \alpha, \beta, \gamma, \pi_{11}, \pi_{12}$ and $\pi_{22}$ into the FOC and imposing that all investors choose the same $c_{2 i}$, we obtain the following expression $\left[-\sigma_{r 2}^{2} \bar{z}_{1} \bar{z}_{2} c_{2}^{2}+\left(\sigma_{r 2}^{2} \sigma_{z 2}^{2}+\sigma_{r 2}^{2} \bar{z}_{2}^{2}-\sigma_{r 1}^{2} \sigma_{z 1}^{2}-\sigma_{r 1}^{2} \bar{z}_{1}^{2}\right) c_{2}+\sigma_{r 1}^{2} \bar{z}_{1} \bar{z}_{2}\right] \times[$ Strictly positive term $]=0$

The optimal solution for $c_{2}$ is

$$
c_{2}^{*}=\frac{\left(\sigma_{r 2}^{2} \sigma_{z 2}^{2}+\sigma_{r 2}^{2} \bar{z}_{2}^{2}-\sigma_{r 1}^{2} \sigma_{z 1}^{2}-\sigma_{r 1}^{2} \bar{z}_{1}^{2}\right)+\sqrt{\left(\sigma_{r 2}^{2} \sigma_{z 2}^{2}+\sigma_{r 2}^{2} \bar{z}_{2}^{2}-\sigma_{r 1}^{2} \sigma_{z 1}^{2}-\sigma_{r 1}^{2} \bar{z}_{1}^{2}\right)^{2}+4 \sigma_{r 1}^{2} \sigma_{r 2}^{2} \bar{z}_{1}^{2} \bar{z}_{2}^{2}}}{2 \sigma_{r 2}^{2} \bar{z}_{1} \bar{z}_{2}}
$$


The SOC under $c_{2}^{*}$

$$
\left[-2 \sigma_{r 2}^{2} \bar{z}_{1} \bar{z}_{2} c_{2}^{*}+\left(\sigma_{r 2}^{2} \sigma_{z 2}^{2}+\sigma_{r 2}^{2} \bar{z}_{2}^{2}-\sigma_{r 1}^{2} \sigma_{z 1}^{2}-\sigma_{r 1}^{2} \bar{z}_{1}^{2}\right)\right] \times[\text { Strictly positive term }]<0
$$

The optimal $c_{2}^{*}$ is always positive. Therefore, there are two necessary conditions in order to have a symmetric equilibrium

$$
\begin{aligned}
& \left(\beta\left(e r_{1} e r_{2}+Q_{12}\right)+\gamma\left(e r_{2}^{2}+Q_{22}\right)\right)>0 \\
& \left(\alpha\left(e r_{1} e r_{2}+Q_{12}\right)+\gamma\left(e r_{1}^{2}+Q_{11}\right)\right)>0
\end{aligned}
$$

which can be rewritten as

$$
Q_{12}>-\bar{Q}
$$

where

$$
\bar{Q}=\max \left\{e r_{1} e r_{2}+\frac{\gamma}{\beta}\left(e r_{2}^{2}+Q_{22}\right), e r_{1} e r_{2}+\frac{\gamma}{\alpha}\left(e r_{1}^{2}+Q_{11}\right)\right\}
$$

The optimal precision of the error term in the private signal is given by equation (15). Substituting $\alpha, \beta, \gamma$ and $c_{2}^{*}$ consistent with the symmetric equilibrium, we obtain the following second order equation of $\Sigma_{i}$ which is

$$
\frac{\left(e^{2 \kappa}-1\right)}{\sigma_{r 1}^{2} \sigma_{r 2}^{2}}(\Sigma)^{2}-\left(\frac{1}{\sigma_{r 2}^{2}}+\frac{c_{2}^{* 2}}{\sigma_{r 1}^{2}}\right) \Sigma+\left(e^{2 \kappa}-1\right)\left(\frac{1}{\sigma_{r 2}^{2}}+\frac{c_{2}^{* 2}}{\sigma_{r 1}^{2}}\right)\left(\frac{\rho^{2}}{\sigma_{z 1}^{2}}+\frac{\rho^{2} c_{2}^{* 2}}{\sigma_{z 2}^{2}}\right)=0
$$

which has two solutions

$$
\Sigma^{*}=\frac{\left(\sigma_{r 1}^{2}+c_{2}^{* 2} \sigma_{r 2}^{2}\right) \pm \sqrt{\left(\sigma_{r 1}^{2}+c_{2}^{* 2} \sigma_{r 2}^{2}\right)\left[\sigma_{r 1}^{2}+c_{2}^{* 2} \sigma_{r 2}^{2}-4 \rho^{2}\left(e^{2 \kappa}-1\right)^{2}\left(\frac{1}{\sigma_{z 1}^{2}}+\frac{c_{2}^{* 2}}{\sigma_{z 2}^{2}}\right)\right]}}{2\left(e^{2 \kappa}-1\right)}
$$

A parameter constraint is required in order to avoid imaginary solutions for the variance 
of the error term, $\Sigma^{*}$, in the private signals. Hence, this constraint is necessary in order to have a symmetric equilibrium

$$
\sigma_{r 1}^{2}+c_{2}^{* 2} \sigma_{r 2}^{2} \geq 4 \rho^{2}\left(e^{2 \kappa}-1\right)^{2}\left(\frac{1}{\sigma_{z 1}^{2}}+\frac{c_{2}^{* 2}}{\sigma_{z 2}^{2}}\right)
$$

Furthermore, both equilibria satisfy the "no-forgetting constraint", which is

$$
\operatorname{Var}(\tilde{R} \mid \tilde{P})-\operatorname{Var}\left(\tilde{R} \mid \tilde{Y}_{i}, \tilde{P}\right) \text { positive semi-definite }
$$

Proof of Proposition 5. There exists a perfect information equilibrium where all investors choose $\Sigma_{i}=0$, which implies that $\tilde{P}=\frac{\tilde{R}}{R}$. The mutual information of asset payoffs and private signal given prices, $I(\tilde{R}, \tilde{Y} \mid \tilde{P})$, is zero because prices are fully revealing. Therefore, the information capacity constraint is always satisfied, which implies that the constraint is never violated. Investors choose the lowest variance of the private signal error, which is $\Sigma_{i}=0$. They are indifferent between any choice of $C_{i}$ since the private signal does not provide any new information. Given that all investors choose $\Sigma_{i}=0$, then prices are fully revealing $\tilde{P}=\frac{\tilde{R}}{R}$.

Proof of Proposition 6. The imperfect information equilibrium $\left(c_{2}^{*}, \Sigma^{L}\right)$ is unstable. Define $\Sigma_{-i}$ as the variance of the error in the private signal of all investors but investor $i$. Then, the optimal variance of the error in the private signal for investor $i$, $\Sigma_{i}$, can be written as

$$
\Sigma_{i}=\frac{\sigma_{r 1}^{2}+c_{2}^{* 2} \sigma_{r 1}^{2}}{\left(e^{2 \kappa}-1\right)\left[1+\left(\sigma_{r 1}^{2}+c_{2}^{* 2} \sigma_{r 1}^{2}\right)\left(\frac{\rho^{2}}{\sigma_{z 1}^{2}}+\frac{\rho^{2} c_{2}^{2}}{\sigma_{z 2}^{2}}\right) \Sigma_{-i}^{-2}\right]}
$$


Therefore:

$$
\begin{aligned}
& \text { If } \Sigma^{L}<\Sigma_{-i}<\Sigma^{H} \Longrightarrow \Sigma_{i}>\Sigma_{-i} \\
& \text { If } \Sigma_{-i}<\Sigma^{L} \Longrightarrow \Sigma_{i}<\Sigma_{-i} \\
& \text { If } \Sigma^{H}<\Sigma_{-i} \Longrightarrow \Sigma_{i}<\Sigma_{-i}
\end{aligned}
$$

Hence, if there is a small perturbation from the equilibrium $\left(c_{2}^{*}, \Sigma^{L}\right)$, this equilibrium is not reached anymore, which implies that it is an unstable equilibrium. By perturbation, I mean that a positive measure of investors deviate from $\Sigma^{L}$ by $\Sigma^{L}+\varepsilon^{n}$ or $\Sigma^{L}-\varepsilon^{n}$ where $\left\{\varepsilon^{n}\right\} \rightarrow 0$. However, this is not true for the imperfect information equilibrium $\left(c_{2}^{*}, \Sigma^{H}\right)$ and the perfect information equilibrium where even if there is a small perturbation of the equilibrium, investors still want to choose the same equilibrium, which implies that they are stable equilibria.

Proof of Proposition 7. There is non-existence of an asymmetric equilibrium. I will characterize the asymmetric equilibria and then I will show that none of them could be sustained as an equilibrium. In an asymmetric equilibrium where there is a fraction $\lambda$ of investors that learn only about the first asset, $C_{\lambda}=(1,0)$ and choose $\Sigma_{\lambda}$ and a fraction $(1-\lambda)$ that learn only about the second asset, $C_{1-\lambda}=(0,1)$ and choose $\Sigma_{1-\lambda}$. To find $\lambda$ we need investors to be indifferent between both corner solutions, which happens when objective function of both types of agents provide the same utility

$$
\frac{\left(e r_{1}^{2}+Q_{11}\right)}{\alpha}=\frac{\left(e r_{2}^{2}+Q_{22}\right)}{\beta}
$$

where

$$
\pi_{11}=\frac{\rho \lambda}{\Sigma_{\lambda}} \quad \pi_{12}=0 \quad \pi_{22}=\frac{\rho(1-\lambda)}{\Sigma_{1-\lambda}}
$$


and

$$
\alpha=\frac{1}{\sigma_{r 2}^{2}}+\frac{\pi_{22}^{2}}{\sigma_{z 2}^{2}} \quad \beta=\frac{1}{\sigma_{r 1}^{2}}+\frac{\pi_{11}^{2}}{\sigma_{z 1}^{2}} \quad \gamma=\frac{\pi_{11} \pi_{12}}{\sigma_{z 1}^{2}}+\frac{\pi_{12} \pi_{22}}{\sigma_{z 2}^{2}}=0
$$

However, this is not an asymmetric equilibrium because the reaction function of the investor in equation (16) would require him to choose

$$
c_{2}=\sqrt{\frac{\alpha}{\beta}}
$$

which implies a utility of $\frac{\left(e r_{1}^{2}+Q_{11}\right)}{\alpha}+\frac{2 e r_{1} e r_{2}}{\sqrt{\alpha \beta}}$ which is a higher utility than choosing $C_{\lambda}$ or $C_{1-\lambda}$ which provide a utility of $\frac{\left(e r_{1}^{2}+Q_{11}\right)}{\alpha}=\frac{\left(e r_{2}^{2}+Q_{22}\right)}{\beta}$. Therefore, the asymmetric equilibrium with specialization is ruled out. We still have to show the non-existence of the other type of asymmetric equilibria. All other asymmetric equilibria can be characterized by having a fraction $\lambda$ of investors that choose $C_{\lambda}=\left(1, c_{2 \lambda}\right)$ and $\Sigma_{\lambda}$ and a fraction $(1-\lambda)$ of investors that choose $C_{1-\lambda}=\left(1, c_{2(1-\lambda)}\right)$ and $\Sigma_{1-\lambda}$. However, as we have seen in Proposition 4, there is a unique solution to the optimal allocation of attention given aggregates $\alpha, \beta, \gamma, \pi^{\prime} s$ which is given by equation (16). Imagine there is an asymmetric equilibrium where a fraction $\lambda$ of investors choose $\left(c_{2 \lambda}, \Sigma_{\lambda}\right)$ and a fraction of investors choose $\left(c_{2(1-\lambda)}, \Sigma_{(1-\lambda)}\right)$. This is not an equilibrium since both types of investors have incentives to deviate to the same equilibrium $\left(c_{2}, \Sigma_{i}\right)$ from equations (15) and (16) found in Proof of Proposition 4.

Proof of Proposition 8. The private signal is given by

$$
\tilde{Y}=\tilde{r}_{1}+c_{2}^{*} \tilde{r}_{2}+\tilde{\varepsilon}_{i}
$$

The relative attention to the first market is given by $\frac{\sigma_{r, 1}^{2}}{c_{2}^{* 2} \sigma_{r, 2}^{2}}$. What matters for the investor is the precision that the private signal is providing about the first market 
relative to the precision that the private signal is providing about the second market.

We need to show that $\frac{\partial c_{2}^{2} \sigma_{r, 2}^{2}}{\partial \sigma_{r, 2}^{2}}>0$ and $\frac{\partial c_{2}^{2} \sigma_{r, 2}^{2}}{\partial \sigma_{z, 2}^{2}}>0$

$$
\begin{aligned}
& \frac{\partial c_{2}}{\partial \sigma_{r, 2}^{2}}=\frac{\left(\sigma_{z, 2}^{2}+\bar{z}_{2}^{2}\right)+\frac{\left(\sigma_{z, 2}^{2}+\bar{z}_{2}^{2}\right)\left(\sigma_{r 2}^{2} \sigma_{z 2}^{2}+\sigma_{r 2}^{2} \bar{z}_{2}^{2}-\sigma_{r 1}^{2} \sigma_{z 1}^{2}-\sigma_{r 1}^{2} \bar{z}_{1}^{2}\right)+2 \sigma_{r 1}^{2} \bar{z}_{2}^{2} \bar{z}_{2}^{2}}{\sqrt{\left(\sigma_{r 2}^{2} \sigma_{z 2}^{2}+\sigma_{r 2}^{2} \bar{z}_{2}^{2}-\sigma_{r 1}^{2} \sigma_{z 1}^{2}-\sigma_{r 1}^{2} \bar{z}_{1}^{2}\right)^{2}+4 \sigma_{r 1}^{2} \sigma_{r 2}^{2} \bar{z}_{1}^{2} \bar{z}_{2}^{2}}}-2 \bar{z}_{1} \bar{z}_{2} c_{2}}{2 \sigma_{r 2}^{2} \bar{z}_{1} \bar{z}_{2}} \\
& \frac{\partial c_{2}^{2} \sigma_{r, 2}^{2}}{\partial \sigma_{r, 2}^{2}}=c_{2}\left(c_{2}+2 \sigma_{r, 2}^{2} \frac{\partial c_{2}}{\partial \sigma_{r, 2}^{2}}\right)= \\
& =c_{2}\left(\frac{2\left(\sigma_{r 2}^{2} \sigma_{z 2}^{2}+\sigma_{r 2}^{2} \bar{z}_{2}^{2}\right)}{2 \sigma_{r 2}^{2} \bar{z}_{1} \bar{z}_{2}}+\frac{\frac{2\left(\sigma_{r 2}^{2} \sigma_{z 2}^{2}+\sigma_{r 2}^{2} \bar{z}_{2}^{2}\right)\left(\sigma_{r 2}^{2} \sigma_{z 2}^{2}+\sigma_{r 2}^{2} \bar{z}_{2}^{2}-\sigma_{r 1}^{2} \sigma_{z 1}^{2}-\sigma_{r 1}^{2} \bar{z}_{1}^{2}\right)+4 \sigma_{r 1}^{2} \bar{z}_{1}^{2} \bar{z}_{2}^{2}}{\sqrt{\left(\sigma_{r 2}^{2} \sigma_{z 2}^{2}+\sigma_{r 2}^{2} \bar{z}_{2}^{2}-\sigma_{r 1}^{2} \sigma_{z 1}^{2}-\sigma_{r 1}^{2} \bar{z}_{1}^{2}\right)^{2}+4 \sigma_{r 1}^{2} \sigma_{r 2}^{2} \bar{z}_{1}^{2} \bar{z}_{2}^{2}}}}{2 \sigma_{r 2}^{2} \bar{z}_{1} \bar{z}_{2}}-c_{2}\right)
\end{aligned}
$$

The terms of interest are inside the parenthesis and can be rewritten as

$$
\begin{gathered}
=\frac{\left(\sigma_{r 2}^{2} \sigma_{z 2}^{2}+\sigma_{r 2}^{2} \bar{z}_{2}^{2}\right)}{2 \sigma_{r 2}^{2} \bar{z}_{1} \bar{z}_{2}}-\frac{\left(\sigma_{r 2}^{2} \sigma_{z 2}^{2}+\sigma_{r 2}^{2} \bar{z}_{2}^{2}-\sigma_{r 1}^{2} \sigma_{z 1}^{2}-\sigma_{r 1}^{2} \bar{z}_{1}^{2}\right)}{2 \sigma_{r 2}^{2} \bar{z}_{1} \bar{z}_{2}}+\frac{\left(\sigma_{r 2}^{2} \sigma_{z 2}^{2}+\sigma_{r 2}^{2} \bar{z}_{2}^{2}\right)}{2 \sigma_{r 2}^{2} \bar{z}_{1} \bar{z}_{2}}+ \\
+\frac{\frac{2\left(\sigma_{r 2}^{2} \sigma_{z 2}^{2}+\sigma_{r 2}^{2} \bar{z}_{2}^{2}\right)\left(\sigma_{r 2}^{2} \sigma_{z 2}^{2}+\sigma_{r 2}^{2} \bar{z}_{2}^{2}-\sigma_{r 1}^{2} \sigma_{z 1}^{2}-\sigma_{r 1}^{2} \bar{z}_{1}^{2}\right)+4 \sigma_{r 1}^{2} \sigma_{r 2}^{2} \bar{z}_{1}^{2} \bar{z}_{2}^{2}}{\sqrt{\left(\sigma_{r 2}^{2} \sigma_{z 2}^{2}+\sigma_{r 2}^{2} \bar{z}_{2}^{2}-\sigma_{r r}^{2} \sigma_{z 1}^{2}-\sigma_{r 1}^{2} \bar{z}_{1}^{2}\right)^{2}+4 \sigma_{r 1}^{2} \sigma_{r 2}^{2} \bar{z}_{1}^{2} \bar{z}_{2}^{2}}}}{2 \sigma_{r 2}^{2} \bar{z}_{1} \bar{z}_{2}}-\frac{\sqrt{\left(\sigma_{r 2}^{2} \sigma_{z 2}^{2}+\sigma_{r 2}^{2} \bar{z}_{2}^{2}-\sigma_{r 1}^{2} \sigma_{z 1}^{2}-\sigma_{r 1}^{2} \bar{z}_{1}^{2}\right)^{2}+4 \sigma_{r 1}^{2} \sigma_{r 2}^{2} \bar{z}_{1}^{2} \bar{z}_{2}^{2}}}{2 \sigma_{r 2}^{2} \bar{z}_{1}^{2} \bar{z}_{2}^{2}}
\end{gathered}
$$

Doing some algebra it is possible to show that this expression is positive. We still have to show that $\frac{\partial c_{2}^{2} \sigma_{r, 2}^{2}}{\partial \sigma_{z, 2}^{2}}>0$.

$$
\begin{gathered}
\frac{\partial c_{2}^{2} \sigma_{r, 2}^{2}}{\partial \sigma_{z, 2}^{2}}=2 c_{2} \sigma_{r, 2}^{2} \frac{\partial c_{2}}{\partial \sigma_{z, 2}^{2}} \\
\frac{\partial c_{2}}{\partial \sigma_{z, 2}^{2}}=\frac{\sigma_{r 2}^{2}\left[1+\frac{\left(\sigma_{r 2}^{2} \sigma_{z 2}^{2}+\sigma_{r 2}^{2} \bar{z}_{2}^{2}-\sigma_{r 1}^{2} \sigma_{z 1}^{2}-\sigma_{r 1}^{2} \bar{z}_{1}^{2}\right)}{\sqrt{\left(\sigma_{r 2}^{2} \sigma_{z 2}^{2}+\sigma_{r 2}^{2} \bar{z}_{2}^{2}-\sigma_{r 1}^{2} \sigma_{z 1}^{2}-\sigma_{r 1}^{2} \bar{z}_{1}^{2}\right)^{2}+4 \sigma_{r 1}^{2} \sigma_{r 2}^{2} \bar{z}_{1}^{2} \bar{z}_{2}^{2}}}\right]}{2 \sigma_{r 2}^{2} \bar{z}_{1}^{2} \bar{z}_{2}^{2}}>0
\end{gathered}
$$

since

$$
1+\frac{\left(\sigma_{r 2}^{2} \sigma_{z 2}^{2}+\sigma_{r 2}^{2} \bar{z}_{2}^{2}-\sigma_{r 1}^{2} \sigma_{z 1}^{2}-\sigma_{r 1}^{2} \bar{z}_{1}^{2}\right)}{\sqrt{\left(\sigma_{r 2}^{2} \sigma_{z 2}^{2}+\sigma_{r 2}^{2} \bar{z}_{2}^{2}-\sigma_{r 1}^{2} \sigma_{z 1}^{2}-\sigma_{r 1}^{2} \bar{z}_{1}^{2}\right)^{2}+4 \sigma_{r 1}^{2} \sigma_{r 2}^{2} \bar{z}_{1}^{2} \bar{z}_{2}^{2}}}>0
$$


Proof of Proposition 9. Under unlearnable risk the objective function in Proposition 2 and the information constraint in equation (6) are the same. The uncertainty of asset payoffs given prices and private information is constrained from below

$$
\log \left|V_{i}\right| \geq \phi \text { where } \phi \in\left(-\infty, \log \left(\sigma_{r, 1}^{2} \sigma_{r, 2}^{2}\right)\right]
$$

In the case that the unlearnable risk constraint is binding, the precision of the error of the private signal is given by

$$
\Sigma_{i}^{-1}=\frac{e^{-\phi}-\left(\alpha \beta-\gamma^{2}\right)}{\left(\alpha c_{1 i}^{2}+\beta c_{2 i}^{2}-2 \gamma c_{1 i} c_{2 i}\right)}
$$

The rest of the results follow from Proposition 4, Proposition 6 and Proposition 5. The optimal attention allocation is the same as in equation (8).

Proof of Proposition 10 and 11. Under unlearnable risk the information capacity constraint is given by

$$
\log |(1-\phi) \Psi|-\log \left|V_{i}-\phi \Psi\right|=2 \kappa
$$

The precision of the error of the private signal can be obtained rearranging the information capacity constraint

$$
\Sigma_{i}^{-1}=\frac{(1-\phi)\left(e^{2 \kappa}-1\right)}{1+\phi\left(e^{2 \kappa}-1\right)} \frac{\left(\alpha \beta-\gamma^{2}\right)}{\left(\alpha c_{1 i}^{2}+\beta c_{2 i}^{2}-2 \gamma c_{1 i} c_{2 i}\right)}
$$

The rest of the results follow from Proposition 4, Proposition 6 and Proposition 5.

Proof of Proposition 12. Financial crises are modelled as an increase in the vari- 
ance of asset payoffs in one market. Therefore, it is enough to show that $\operatorname{Var}\left[\tilde{r}_{1} \mid \tilde{Y}, \tilde{P}\right]$ is increasing in $\sigma_{r, 2}^{2}$ in order to prove volatility contagion when a region is hit by a financial crisis. Doing some algebra we obtain

$$
\operatorname{Var}\left[\tilde{r}_{1} \mid \tilde{Y}_{i}, \tilde{P}\right]=\frac{1}{\frac{1}{\sigma_{r, 1}^{2}}+\frac{\left[\left(\frac{\rho^{2}}{\sigma_{z 1}^{2}}+\frac{\rho^{2} c_{2}^{* 2}}{\sigma_{z 2}^{2}}\right) \frac{1}{\Sigma^{H 2}}+\frac{1}{\Sigma^{H}}\right]}{1+c_{2}^{* 2} \sigma_{r, 2}^{2}\left(\left(\frac{\rho^{2}}{\sigma_{z 1}^{2}}+\frac{\rho^{2} c_{2}^{* 2}}{\sigma_{z 2}^{2}}\right) \frac{1}{\Sigma^{H 2}}+\frac{1}{\Sigma^{H}}\right)}}
$$

After some algebra, it is possible to show

$$
\frac{\partial\left[\left(\frac{\rho^{2}}{\sigma_{z 1}^{2}}+\frac{\rho^{2} c_{2}^{* 2}}{\sigma_{z 2}^{2}}\right) \frac{1}{\Sigma^{H^{2}}}+\frac{1}{\Sigma^{H}}\right]}{\partial \sigma_{r, 2}^{2}}<0 \text { if } \sigma_{r, 2}^{2}>\frac{4 \rho^{2}\left(e^{2 \kappa}-1\right)}{\sigma_{z, 2}^{2}}
$$

which is enough to prove that

$$
\frac{\partial \operatorname{Var}\left[\tilde{r}_{1} \mid \tilde{Y}, \tilde{P}\right]}{\partial \sigma_{r, 2}^{2}}>0 \text { if } \sigma_{r, 2}^{2}>\frac{4 \rho^{2}\left(e^{2 \kappa}-1\right)}{\sigma_{z, 2}^{2}}
$$

Proof of Proposition 13. Assume both countries are symmetric, which means that $\sigma_{r 1}^{2}=\sigma_{r 2}^{2}, \sigma_{z 1}^{2}=\sigma_{z 2}^{2}$ and $\bar{z}_{1}=\bar{z}_{2}$. Financial crises are modelled as an increase in the variance of asset payoffs in one market. Expected asset prices that can be written as

$$
\begin{aligned}
& \bar{p}_{1}=\frac{1}{R}\left(\bar{r}_{1}-e r_{1}\right)=\frac{\bar{r}_{1}-\frac{\bar{z}_{1}}{\rho} \operatorname{Var}\left(\tilde{r}_{1} \mid \tilde{Y}, \tilde{P}\right)-\frac{\bar{z}_{2}}{\rho c_{2}^{*}} \operatorname{Cov}\left(\tilde{r}_{1}, \tilde{r}_{2} \mid \tilde{Y}, \tilde{P}\right)}{R} \\
& \bar{p}_{2}=\frac{1}{R}\left(\bar{r}_{2}-e r_{2}\right)=\frac{\bar{r}_{2}-\frac{\bar{z}_{2}}{\rho} \operatorname{Var}\left(\tilde{r}_{2} \mid \tilde{Y}, \tilde{P}\right)-\frac{\bar{z}_{1}}{\rho} \operatorname{Cov}\left(\tilde{r}_{1}, \tilde{r}_{2} \mid \tilde{Y}, \tilde{P}\right)}{R}
\end{aligned}
$$

Therefore, it is enough to show that $e r_{1}$ and $e r_{2}$ are increasing in $\sigma_{r 1}^{2}$ in order to prove that both expected prices fall when a region is hit by a financial crisis. Doing some 
algebra we obtain

$$
\begin{aligned}
& e r_{1}=\frac{\rho \sigma_{r 1}^{2} \bar{z}_{1}}{\rho^{2}+\left(\sigma_{r 1}^{2}+\sigma_{r 2}^{2}\right)\left(\frac{\rho^{4}}{\sigma_{z 1}^{2} \Sigma^{H 2}}+\frac{\rho^{4}}{\sigma_{z 2}^{2} \Sigma^{H 2}}+\frac{\rho^{2}}{\Sigma^{H}}\right)} \\
& e r_{2}=\frac{\rho \sigma_{r 2}^{2} \bar{z}_{2}}{\rho^{2}+\left(\sigma_{r 1}^{2}+\sigma_{r 2}^{2}\right)\left(\frac{\rho^{4}}{\sigma_{z 1}^{2} \Sigma^{H 2}}+\frac{\rho^{4}}{\sigma_{z 2}^{2} \Sigma^{H 2}}+\frac{\rho^{2}}{\Sigma^{H}}\right)}
\end{aligned}
$$

taking into account that

$$
\Sigma^{H}=\frac{\left(\sigma_{r 1}^{2}+\sigma_{r 2}^{2}\right)+\sqrt{\left(\sigma_{r 1}^{2}+\sigma_{r 2}^{2}\right)\left[\sigma_{r 1}^{2}+\sigma_{r 2}^{2}-4 \rho^{2}\left(e^{2 \kappa}-1\right)^{2}\left(\frac{1}{\sigma_{z 1}}+\frac{1}{\sigma_{z 2}}\right)\right]}}{2\left(e^{2 \kappa}-1\right)}
$$

it can be shown that

$$
\frac{\partial \Sigma^{H}}{\partial \sigma_{r 1}^{2}}>0 \quad \text { and } \quad \frac{\partial\left(\frac{1}{\Sigma^{H}}+\frac{\sigma_{r 1}^{2}}{\sigma_{r 2}^{2} \Sigma^{H}}\right)}{\partial \sigma_{r 1}^{2}}<0
$$

which implies that

$$
\frac{\partial e r_{1}}{\partial \sigma_{r 1}^{2}}>0 \quad \frac{\partial e r_{2}}{\partial \sigma_{r 1}^{2}}>0
$$

and therefore expected asset prices are decreasing

$$
\frac{\partial \bar{p}_{1}}{\partial \sigma_{r 1}^{2}}<0 \quad \frac{\partial \bar{p}_{2}}{\partial \sigma_{r 1}^{2}}<0
$$

Proof of Proposition 14. If there is a financial crisis, then expected prices decrease as shown in Proposition 13. Since all agents are identical and the asset supply is inelastic, the asset holdings remain the same as if there was not a financial crisis. 
Therefore, the expected wealth allocated to bond holdings increases.

$$
x_{\text {bonds }}=W_{0}-\bar{z}_{1} \bar{p}_{1}-\bar{z}_{2} \bar{p}_{2}
$$

where $\bar{z}_{1}$ and $\bar{z}_{2}$ are constant and $\bar{p}_{1}$ and $\bar{p}_{2}$ decrease.

Proof of Proposition 15. First, let's write the optimization problem. The objective function becomes

$$
\max _{\kappa_{i}} \operatorname{Tr}\left(\frac{1}{2} V_{i}^{-1} Q\right)+\frac{1}{2} E R^{\prime} V_{i}^{-1} E R+\frac{R W_{0, i}}{\rho_{i}}-\frac{R}{\rho_{i}} c\left(\kappa_{i}\right)
$$

subject to information constraint (15). Taking FOC, we obtain the implicit equation that solves for $\kappa$

$$
\frac{2\left[\left(e r_{1}^{2}+Q_{11}\right)+\left(e r_{2}^{2}+Q_{22}\right) c_{2 i}^{2}+2\left(e r_{1} e r_{2}+Q_{12}\right) c_{2 i}\right]\left(\alpha \beta-\gamma^{2}\right)}{\alpha+\beta c_{2 i}^{2}-2 \gamma c_{2 i}} e^{2 \kappa_{i}}-\frac{R}{\rho_{i}} c^{\prime}\left(\kappa_{i}\right)=0
$$

given that $c_{2}, e r_{1}, e r_{2}, \alpha, \beta, \gamma, \Sigma_{i}^{-1}, \pi_{11}, \pi_{12}$ and $\pi_{22}$ are given by equations (8), (12), (13), (15) and (14). After that we still have to find the fix point where all investors choose the same information processing capacity and attention allocation. 


\section{References}

[1] Admati, A. (1985). A Noisy Rational Expectations Equilibrium for Multi-Asset Securities Markets. Econometrica, 53, pp. 629-657.

[2] Allen, F., Gale, D. (2000). Financial Contagion. Journal of Political Economy, 108, pp. 1-33.

[3] Brunnermeier, M. (2001). Asset Pricing under Asymmetric Information. Oxford University Press.

[4] Calvo, G. (1999). Contagion in Emerging Markets: when Wall Street is a Carrier. Working Paper, University of Maryland.

[5] Calvo, G., Mendoza, E. (2000a). Capital-Market Crises and Economic Collapse in Emerging Markets: an Informational-Frictions Approach. American Economic Review, 90, pp. 59-64.

[6] Calvo, G., Mendoza, E. (2000b). Rational contagion and the globalization of securities markets. Journal of International Economics, 51, pp. 79-113.

[7] Gabaix, X., Laibson, D. (2001). The 6D Bias and the Equity Premium Puzzle. NBER Macroeconomics Annual 2001, pp. 257-311.

[8] Grossman, S., Stiglitz, J. (1980). On the impossibility of Informationally Efficient Markets. The American Economic Review, 70, pp. 393-408.

[9] Hansen, L., Sargent, T. (1995). Discounted Linear Exponential Quadratic Gaussian Control. IEEE Transactions on Automatic Control, 40, pp. 968-971.

[10] Hansen, L., Sargent, T. (2004). Recursive Models of Dynamic Linear Economies. Monograph June 2004. 
[11] Kaminsky, G., Reinhart, C. (2000). On Crises, Contagion, and Confusion. Journal of International Economics, 51, pp. 145-168.

[12] Kaminsky, G., Reinhart, C., Vegh, C. (2003). The Unholy Trinity of Financial Contagion. NBER working paper w10061.

[13] Kaminsky, G., Schmukler, S. (1999). What Triggers Market Jitters? A Chronicle of the Asian Crisis. Journal of International Money and Finance, 18, pp. 537-560.

[14] Khinchin, A. (1957). Mathematical Foundations of Information Theory. Dover Publications, Inc., New York.

[15] King, M., Wadhwani, S. (1990). Transmission of Volatility between Stock Markets. Review of Financial Studies, 3, pp. 5-33.

[16] Kreps, D., Porteus, E. (1978). Temporal Resolution of Uncertainty and Dynamic Choice Theory. Econometrica, 46, pp. 185-200.

[17] Kreps, D., Porteus, E. (1979). Temporal von Neumann-Morgenstern and Induced Preferences. Journal of Economic Theory, 20, pp. 81-109.

[18] Kodres, L., Pritsker, M. (2002). A Rational Expectations Model of Financial Contagion. Journal of Finance, 57, pp. 769-799.

[19] Kyle, A., Xiong, W. (2001). Contagion as a Wealth Effect. Journal of Finance, 56, pp. 1401-1440.

[20] Luo, Y. (2005). Consumption Dynamics under Information Processing Constraints. Working paper, Princeton University.

[21] Machina, M. (1984). Temporal Risk and the Nature of Induced Preferences. Journal of Economic Theory, 33, pp. 199-231. 
[22] Mankiw, G., Reis, R. (2002). Sticky Information Versus Sticky Prices: A Proposal to Replace the New Keynesian Phillips Curve. Quarterly Journal of Economics, 117, pp. 1295-1328.

[23] Mankiw, G., Reis, R. (2003). Sticky Information: A Model of Monetary Nonneutrality and Structural Slumps. Knowledge, Information, and Expectations in Modern Macroeconomics: In Honor of Edmund S. Phelps. Princeton University Press.

[24] Peng, L. (2005). Learning with Information Capacity Constraints. Journal of Financial and Quantitative Analysis, forthcoming.

[25] Peng, L., Xiong, W. (2005). Investor Attention, Overconfidence and Category Learning. Journal of Financial Economics, forthcoming.

[26] Reis, R. (2004). Inattentive Consumers. NBER working paper 10883.

[27] Reis, R. (2005). Inattentive Producers. Working paper, Princeton University.

[28] Reza, F. (1994). An Introduction of Information Theory. Dover Publications, Inc., New York.

[29] Rigobon, R., Wei, S. (2003). News, Contagion, and Anticipation. Journal of Economic Literature, forthcoming.

[30] Sims, C. (2003). Implications of Rational Inattention. Journal of Monetary Economics, 50, pp. 665-690.

[31] Sims, C. (2005). Rational Inattention: A Research Agenda. Working paper, Princeton University. 
[32] Spence, M., Zeckhauser, R. (1972). The Effect of the Timing of Consumption Decisions and the Resolution of Lotteries on the Choice of Lotteries. Econometrica, 40, pp. 401-403.

[33] Van Nieuwerburgh, S., Veldkamp, L. (2005a). Information Acquisition and Portfolio Under-Diversification. Working Paper, NYU.

[34] Van Nieuwerburgh, S., Veldkamp, L. (2005b). Information Immobility and the Home Bias Puzzle. Working Paper, NYU.

[35] Veldkamp, L. (2004). Media Frenzies in Markets for Financial Information. Working Paper, NYU.

[36] Verrecchia, R. (1982). Information Acquisition in a Noisy Rational Expectations Economy. American Economic Review, 50, pp. 1415-1430.

[37] Weil, P. (1990). Nonexpected Utility in Macroeconomics. Quarterly Journal of Economics, 105, pp. 29-42.

[38] Weil, P. (1993). Precautionary Savings and the Permanent Income Hypothesis. The Review of Economic Studies, 60, pp. 367-383.

[39] Yuan, K. (2000). Asymmetric Price Movements and Borrowing Constraints: A REE Model of Crisis, Contagion, and Confusion. Journal of Finance, forthcoming. 


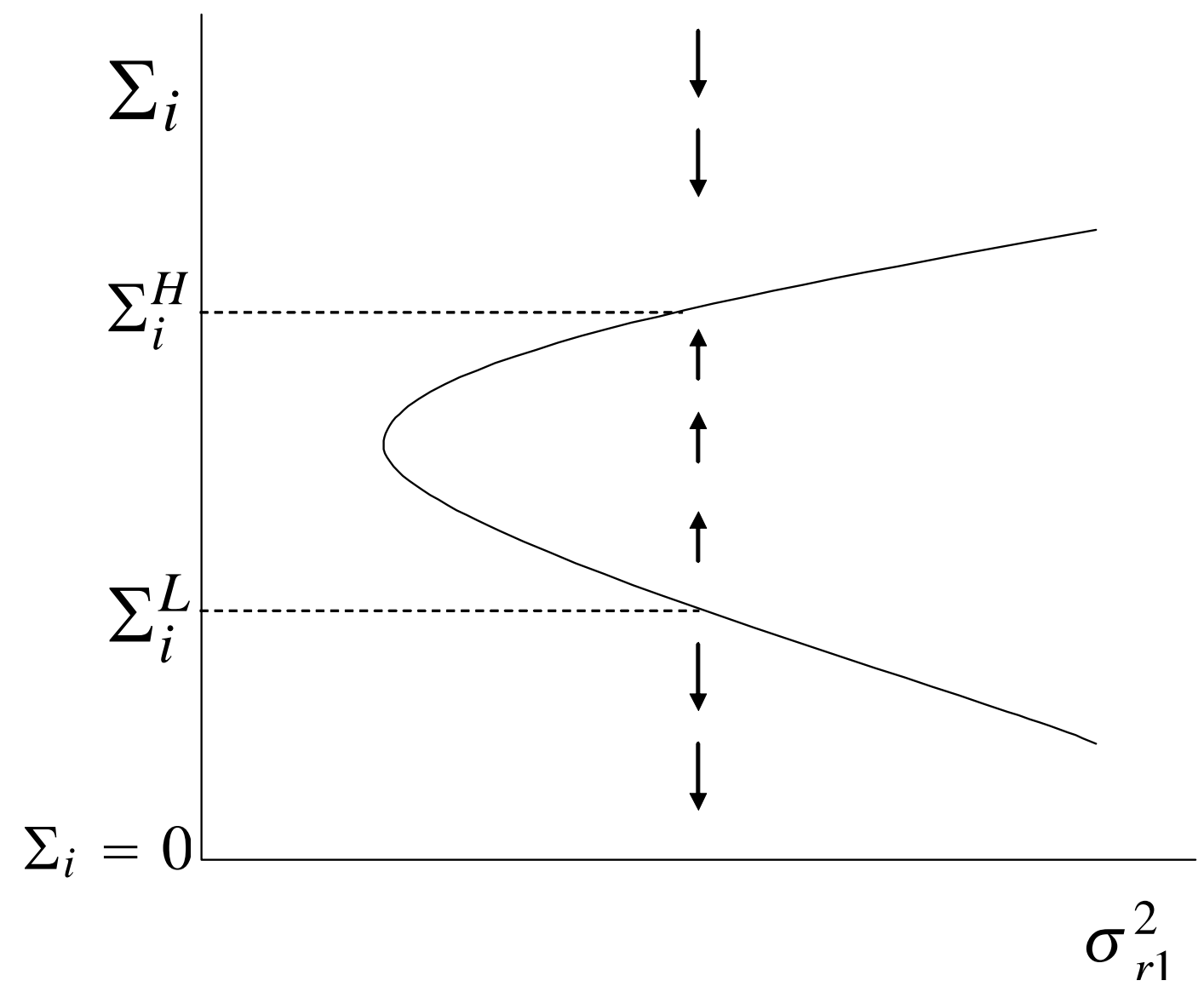

Figure 1: Two Stable Equilibria 


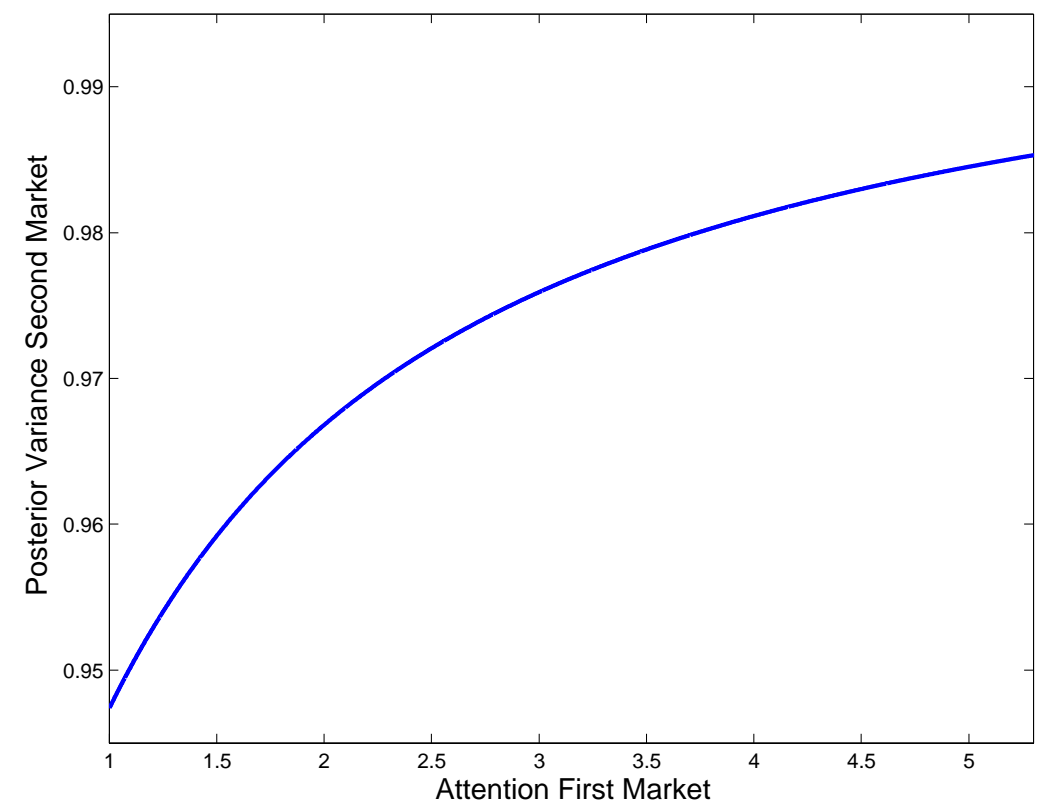

Figure 2: Volatility Contagion through Attention Allocation

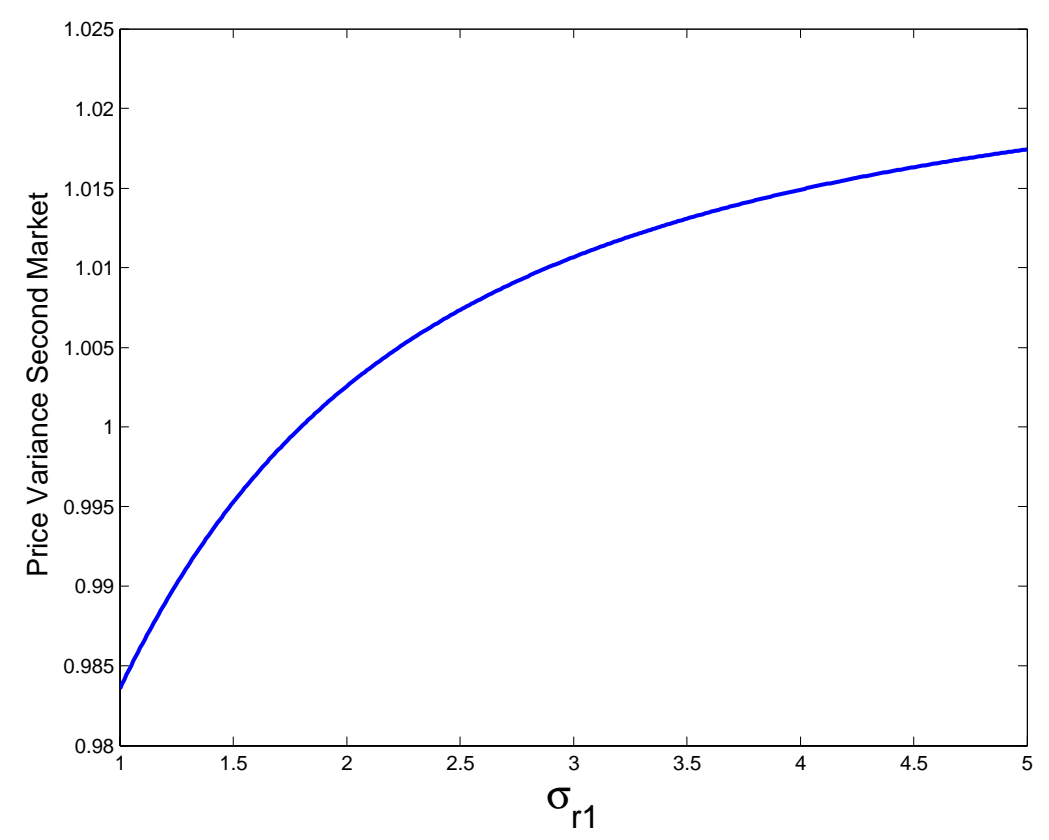

Figure 3: Volatility Contagion through Attention Allocation 


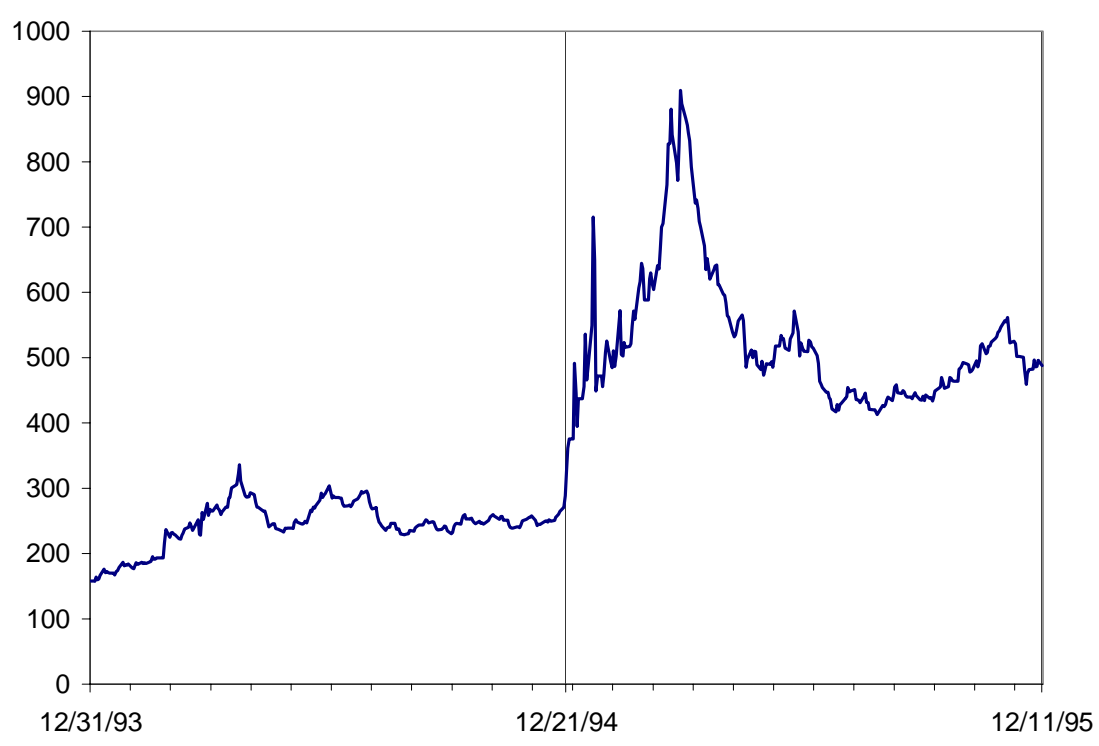

Figure 4: JP Morgan EMBI+ Mexico

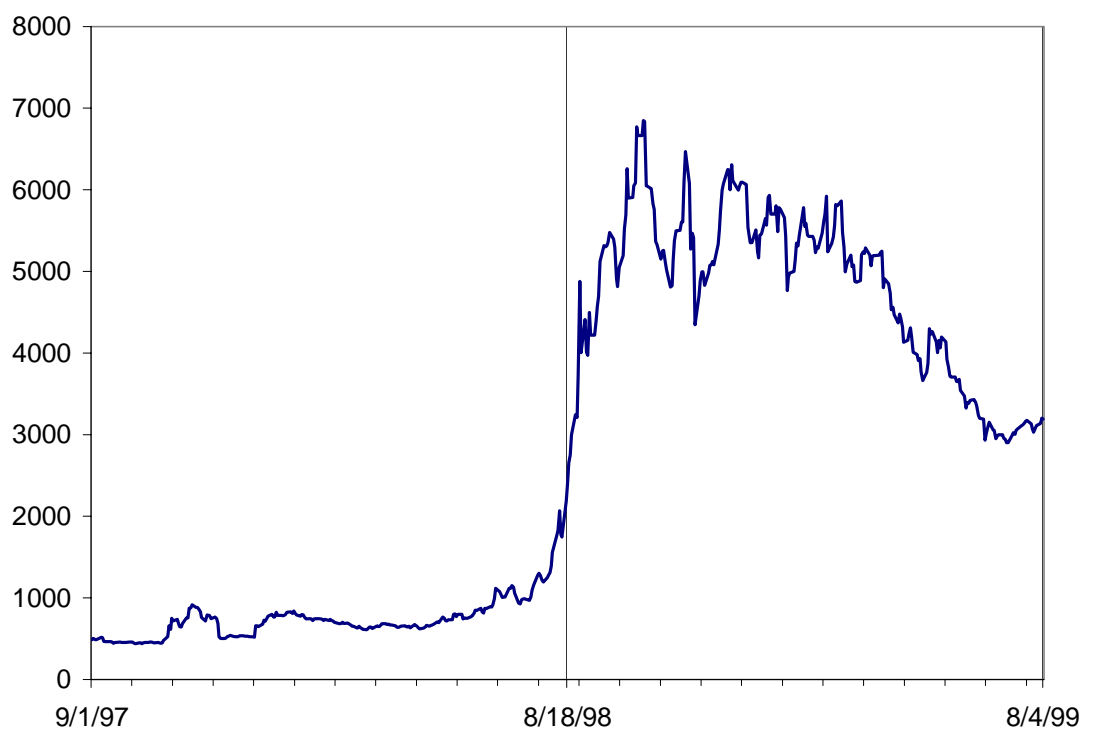

Figure 5: JP Morgan EMBI+ Russia 


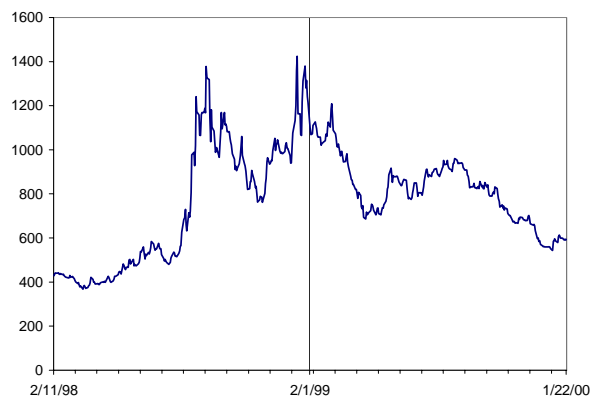

Figure 6: JP Morgan EMBI+ Brazil

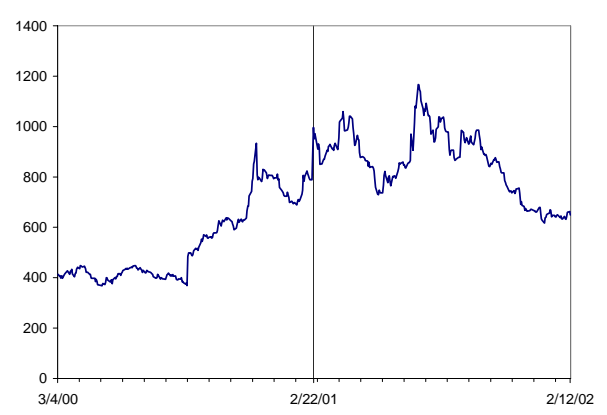

Figure 7: JP Morgan EMBI+ Turkey

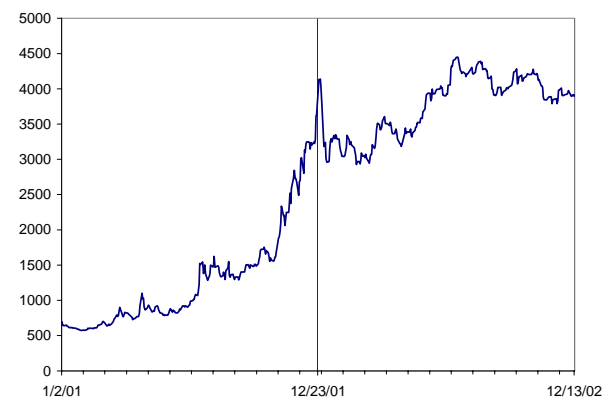

Figure 8: JP Morgan EMBI+ Argentina 


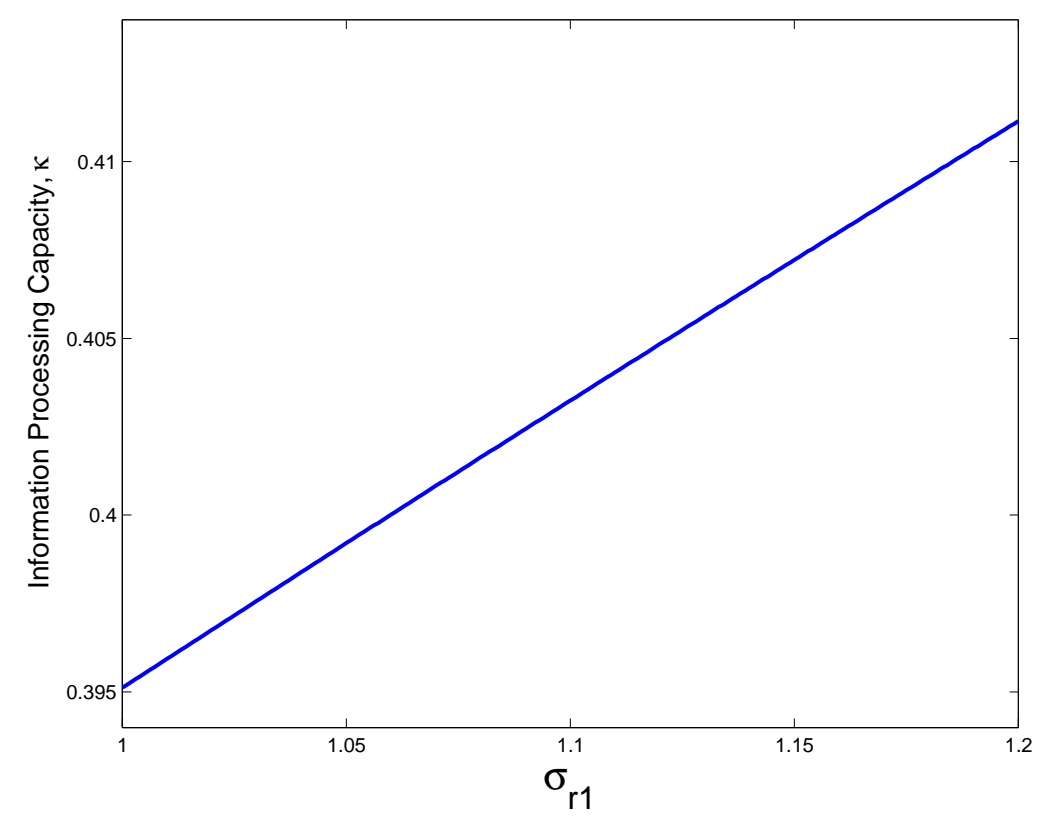

Figure 9: Optimal Information Processing Capacity

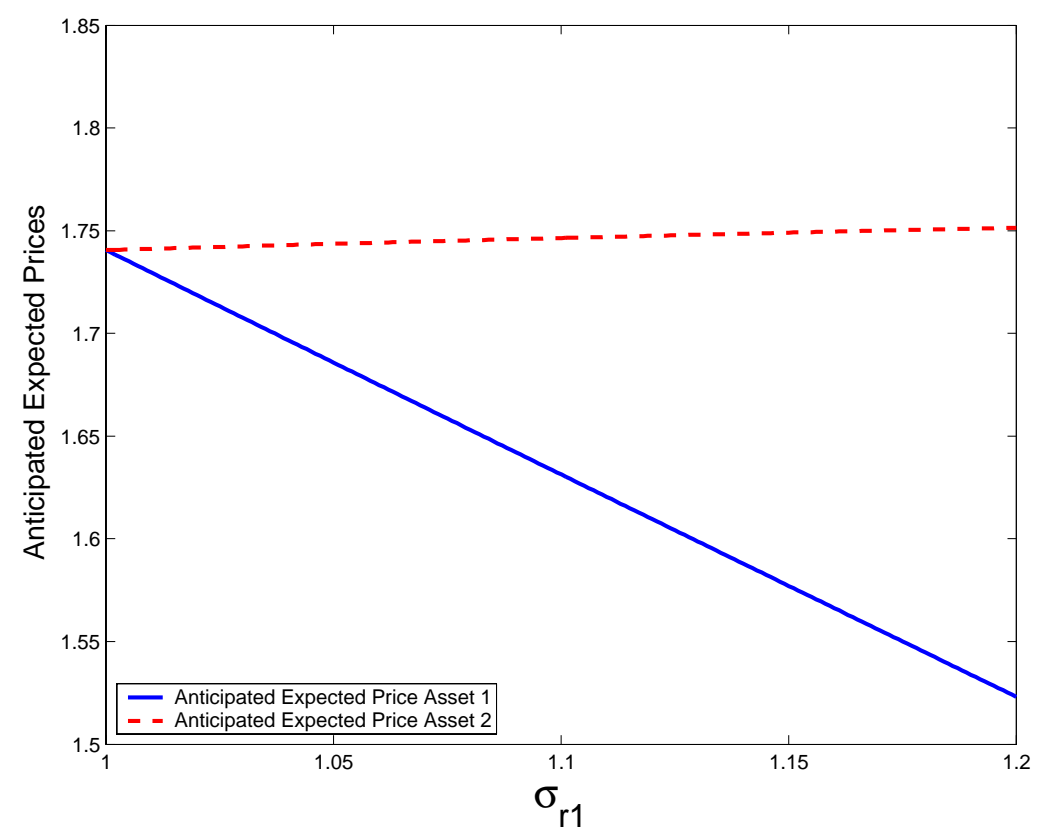

Figure 10: Anticipated Expected Prices 


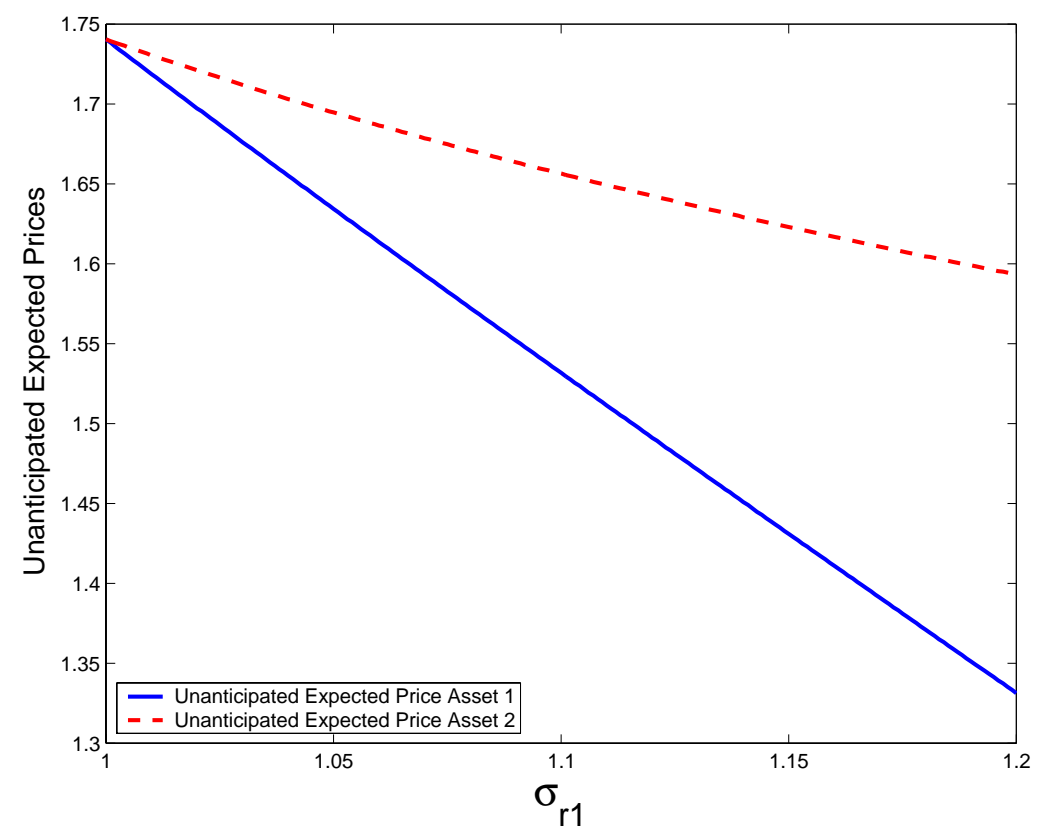

Figure 11: Unanticipated Expected Prices

Table 1: Descriptive Statistics

\begin{tabular}{|c|c|c|c|c|c|c|c|c|c|c|c|c|}
\hline & \multicolumn{4}{|c|}{ Number of News $t$} & \multicolumn{4}{|c|}{ Total Return Index } & \multicolumn{4}{|c|}{ Volatility Return Index } \\
\hline Country & mean & stdev & $\min$ & $\max$ & mean & stdev & $\min$ & $\max$ & mean & stdev & $\min$ & $\max$ \\
\hline Brazil & 4.97 & 3.42 & 0 & 26 & 113.59 & 15.10 & 86.52 & 143.02 & 0.01 & 0.01 & 0.00 & 0.11 \\
\hline Chile & 1.4 & 1.39 & 0 & 9 & 113.14 & 13.11 & 86.37 & 135.85 & 0.01 & 0.01 & 0.00 & 0.06 \\
\hline Thailand & 4.67 & 2.92 & 0 & 24 & 57.26 & 23.74 & 21.19 & 104.88 & 0.03 & 0.03 & 0.00 & 0.16 \\
\hline
\end{tabular}


Table 2: Trade Links

Total Trade of Thailand and Argentina $=0.07 \%$ of Argentinean GDP

Total Trade of Thailand and Brazil $=0.07 \%$ Brazilian GDP

Total Trade of Thailand and Chile $=0.21 \%$ Chilean GDP

Total Trade of Thailand and Argentina $=0.1 \%$ of Thai GDP

Total Trade of Thailand and Brazil $=0.3 \%$ Thai GDP

Total Trade of Thailand and Chile $=0.08 \%$ Thai GDP

Table 3: Thai News

\begin{tabular}{|c|c|c|c|c|c|}
\hline \multirow{2}{*}{$\begin{array}{l}\text { Dependent Variable } \\
\text { Explanatory Variables }\end{array}$} & \multicolumn{2}{|c|}{ News $_{t}$} & \multirow{2}{*}{$\begin{array}{c}\sqrt{\mathrm{News}_{t}} \\
\mathrm{OLS} \\
(3)\end{array}$} & \multirow{2}{*}{$\begin{array}{c}\operatorname{Ln}\left(\text { News }_{t}+0.1\right) \\
\text { OLS } \\
(4)\end{array}$} & \multirow{2}{*}{$\begin{array}{c}\operatorname{Ln}\left(\mathrm{News}_{t}\right)^{*} \mathrm{D}_{1} \\
\text { OLS } \\
(5)\end{array}$} \\
\hline & $\begin{array}{c}\text { OLS } \\
(1) \\
\end{array}$ & $\begin{array}{c}\text { OLS } \\
(2) \\
\end{array}$ & & & \\
\hline 1st Lag & & $\begin{array}{c}0.06 \\
(0.04)\end{array}$ & $\begin{array}{c}0.08 \\
(0.05)\end{array}$ & $\begin{array}{c}0.12 \\
(0.08)\end{array}$ & $\begin{array}{c}0.06 \\
(0.05)\end{array}$ \\
\hline 2nd Lag & & $\begin{array}{c}0.17^{* * *} \\
(0.05)\end{array}$ & $\begin{array}{c}0.15^{* * *} \\
(0.05)\end{array}$ & $\begin{array}{c}0.09 \\
(0.06)\end{array}$ & $\begin{array}{c}0.19^{* * *} \\
(0.05)\end{array}$ \\
\hline Thai Volatility $_{t-1}$ & $\begin{array}{c}24.98^{* * *} \\
(6.17)\end{array}$ & $\begin{array}{l}19^{* * *} \\
(6.09)\end{array}$ & $\begin{array}{c}4.85^{* * *} \\
(1.31)\end{array}$ & $\begin{array}{c}5.6^{* * *} \\
(1.44)\end{array}$ & $\begin{array}{l}4.5^{* * *} \\
(1.13)\end{array}$ \\
\hline F-Statistic for & & & & & \\
\hline Granger Causality & & $9.73^{* * *}$ & $13.68^{* * *}$ & $15.01^{* * *}$ & $15.75^{* * *}$ \\
\hline R-Squared & $5.1 \%$ & $8.57 \%$ & $8.55 \%$ & $7.5 \%$ & $9.34 \%$ \\
\hline Number of Observations & 388 & 388 & 388 & 388 & 388 \\
\hline
\end{tabular}

Note: Robust Standard errors allowing for heteroskedasticity are reported in parentheses.

$\mathrm{D}_{1}=1$ if Thai News $>0$ and $\mathrm{D}_{1}=0$ if Thai News $=0$

Volatility is calculated as the absolute value of $(\log ($ Return Index $t)-\log ($ Return Index t-1)).

*** Significant at $1 \%,{ }^{* *}$ Significant at $5 \%,{ }^{*}$ Significant at $10 \%$. 
Table 4: Brazilian Stock Market Volatility and Thai News

\begin{tabular}{|c|c|c|c|c|c|}
\hline \multirow{3}{*}{$\begin{array}{l}\text { Dependent Variable } \\
\text { Explanatory Variables }\end{array}$} & \multicolumn{5}{|c|}{ 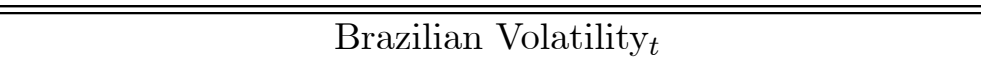 } \\
\hline & OLS & OLS & OLS & OLS & OLS \\
\hline & (1) & (2) & (3) & (4) & (5) \\
\hline Thai News $t$ & $\begin{array}{c}0.0007^{* *} \\
(0.0003)\end{array}$ & $\begin{array}{c}0.0015^{* * *} \\
(0.0004)\end{array}$ & & & \\
\hline$(\text { Thai News } t)^{2}$ & & $\begin{array}{c}-6.81 \mathrm{E}-05^{* * *} \\
(2.2 \mathrm{E}-05)\end{array}$ & & & \\
\hline$\sqrt{\text { Thai Newst }}$ & & & $\begin{array}{c}0.003^{* * *} \\
(0.001)\end{array}$ & & \\
\hline $\operatorname{Ln}\left(\right.$ Thai $\left.\mathrm{News}_{t}+0.1\right)$ & & & & $\begin{array}{c}0.0023^{* * *} \\
(0.0007)\end{array}$ & \\
\hline $\operatorname{Ln}($ Thai News $t) * D_{1}$ & & & & & $\begin{array}{c}0.003^{* * *} \\
(0.001)\end{array}$ \\
\hline R-Squared & $1.88 \%$ & $2.6 \%$ & $2.15 \%$ & $1.86 \%$ & $2.22 \%$ \\
\hline Number of Observations & 389 & 389 & 389 & 389 & 389 \\
\hline
\end{tabular}

Note: Robust Standard errors allowing for heteroskedasticity are reported in parentheses.

Volatility is calculated as the ( $\log ($ Return Index t) $-\log ($ Return Index t-1)).

$\mathrm{D}_{1}=1$ if Thai News $>0$ and $\mathrm{D}_{1}=0$ if Thai News $=0$

*** Significant at $1 \%,{ }^{* *}$ Significant at $5 \%, *$ Significant at $10 \%$. 
Table 5: Brazilian Stock Market Volatility and Thai News

\begin{tabular}{|c|c|c|c|c|c|}
\hline 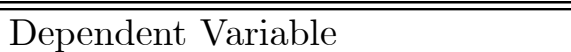 & & & rezilian Vola & $\overline{\overline{\text { tility }_{t}}}$ & \\
\hline & $\begin{array}{c}\text { OLS } \\
(1)\end{array}$ & $\begin{array}{c}\text { OLS } \\
(2)\end{array}$ & $\begin{array}{l}\text { OLS } \\
(3)\end{array}$ & $\begin{array}{c}\text { OLS } \\
(4)\end{array}$ & $\begin{array}{c}\text { OLS } \\
(5)\end{array}$ \\
\hline Thai News $_{t}$ & $\begin{array}{c}0.0006^{* *} \\
(0.0003)\end{array}$ & $\begin{array}{c}0.0006^{* *} \\
(0.0003)\end{array}$ & $\begin{array}{c}0.0012^{* * *} \\
(0.0004)\end{array}$ & $\begin{array}{c}0.0011^{* * *} \\
(0.0004)\end{array}$ & $\begin{array}{c}0.001^{* * *} \\
(0.0004)\end{array}$ \\
\hline$(\text { Thai News } t)^{2}$ & & & $\begin{array}{c}-0.00004^{* *} \\
(0.00002)\end{array}$ & $\begin{array}{c}-0.00004^{* *} \\
(0.00002)\end{array}$ & $\begin{array}{c}-0.00004^{* *} \\
(0.00002)\end{array}$ \\
\hline $\begin{array}{l}\text { Control Variables? } \\
\text { US Interest Rates } \\
\text { HK dummy } \\
\text { Brazilian News } \\
\text { Thai Volatility } t \\
\text { Thai Volatility }_{t-1} \\
\text { Asian Volatility } \\
\text { Asian Volatility } t-1 \\
\end{array}$ & Yes & Yes & Yes & Yes & Yes \\
\hline 3 Brazilian Volatility Lags? & No & Yes & No & Yes & Yes \\
\hline Squared Variables? & No & No & No & No & Yes \\
\hline $\begin{array}{l}\text { F-Statistic for Granger Causality } \\
\text { R-Squared } \\
\text { Number of Observations }\end{array}$ & $\begin{array}{c}9.84 \% \\
388\end{array}$ & $\begin{array}{c}20.61 \% \\
386\end{array}$ & $\begin{array}{c}10.17 \% \\
388\end{array}$ & $\begin{array}{c}4.00^{* *} \\
20.85 \% \\
386\end{array}$ & $\begin{array}{c}3.59^{* *} \\
22.09 \% \\
386\end{array}$ \\
\hline
\end{tabular}

Note: Robust Standard errors allowing for heteroskedasticity are reported in parentheses.

Volatility is calculated as the absolute value of $(\log ($ Return Index $t)-\log ($ Return Index t-1)).

Squared Variables: Brazil News, Thai Volatility t and t-1, Asian Volatility t and t-1.

*** Significant at $1 \%, * *$ Significant at $5 \%, *$ Significant at $10 \%$. 
Table 6: Brazilian Stock Market Volatility and Thai News

\begin{tabular}{|c|c|c|c|c|c|c|}
\hline 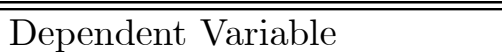 & & & Braziliar & 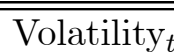 & & \\
\hline & $\begin{array}{c}\text { OLS } \\
(1)\end{array}$ & $\begin{array}{c}\text { OLS } \\
(2)\end{array}$ & $\begin{array}{c}\text { OLS } \\
(3)\end{array}$ & $\begin{array}{c}\text { OLS } \\
(4)\end{array}$ & $\begin{array}{c}\text { OLS } \\
(5)\end{array}$ & $\begin{array}{c}\text { OLS } \\
(6)\end{array}$ \\
\hline$\sqrt{\text { Thai News }_{t}}$ & $\begin{array}{c}0.0023^{* *} \\
(0.001)\end{array}$ & $\begin{array}{c}0.0022^{* *} \\
(0.001)\end{array}$ & & & & \\
\hline $\operatorname{Ln}\left(\right.$ Thai $\left.\mathrm{News}_{t}+0.1\right)$ & & & $\begin{array}{c}0.0017^{* *} \\
(0.0007)\end{array}$ & $\begin{array}{c}0.002^{* * *} \\
(0.0007)\end{array}$ & & \\
\hline $\operatorname{Ln}($ Thai News $t) * D_{1}$ & & & & & $\begin{array}{c}0.0025^{* * *} \\
(0.0009)\end{array}$ & $\begin{array}{c}0.0026^{* * *} \\
(0.001)\end{array}$ \\
\hline $\begin{array}{l}\text { Control Variables? } \\
\text { US Interest Rates } \\
\text { HK dummy } \\
3 \text { Brazilian Volatility Lags }\end{array}$ & Yes & Yes & Yes & Yes & Yes & Yes \\
\hline $\begin{array}{l}\text { Linear Controls? } \\
\text { Brazilian News } \\
\text { Thai Volatility t and t-1 } \\
\text { Asian Volatility t and t-1 }\end{array}$ & Yes & No & Yes & No & Yes & No \\
\hline $\begin{array}{l}\text { Transformed Controls? } \\
\text { F(Brazilian News } \text { N }_{t} \text { ) } \\
\text { F(Thai Volatility) t and } t-1 \\
\text { F(Asian Volatility) t and } t-1\end{array}$ & No & Yes & No & Yes & No & Yes \\
\hline $\begin{array}{l}\text { R-Squared } \\
\text { Number of Observations }\end{array}$ & $\begin{array}{l}20.7 \% \\
386\end{array}$ & $\begin{array}{c}21.1 \% \\
386\end{array}$ & $\begin{array}{c}20.5 \% \\
386\end{array}$ & $\begin{array}{c}20.78 \% \\
386\end{array}$ & $\begin{array}{c}20.75 \% \\
386\end{array}$ & $\begin{array}{c}21.3 \% \\
386\end{array}$ \\
\hline
\end{tabular}

Note: Robust Standard errors allowing for heteroskedasticity are reported in parentheses.

Volatility is calculated as the absolute value of $(\log ($ Return Index t) - $\log ($ Return Index t-1)).

$\mathrm{D}_{1}=1$ if Thai News $>0$ and $\mathrm{D}_{1}=0$ if Thai News $=0$

Transformed Variables: Brazilian News, Thai and Asian Volatility same functional form as Thai News.

*** Significant at $1 \%, * *$ Significant at $5 \%, *$ Significant at $10 \%$. 
Table 7: Chilean Stock Market Volatility and Thai News

\begin{tabular}{|c|c|c|c|c|c|}
\hline Dependent Variable & & & ean Volati & & \\
\hline Fynlanatory Variables & OLS & OLS & OLS & OLS & OLS \\
\hline Thai News $s_{t}$ & 0.00014 & $\begin{array}{c}0.00066^{* * *} \\
(0.00021)\end{array}$ & & & \\
\hline$\left.(\text { Thai News })_{t}\right)^{2}$ & & $\begin{array}{c}-0.00004^{* * *} \\
(0.00001)\end{array}$ & & & \\
\hline$\sqrt{\text { Thai Newst }}$ & & & $\begin{array}{l}0.00089^{* *} \\
(0.00038)\end{array}$ & & \\
\hline $\operatorname{Ln}\left(\right.$ Thai $\left.\operatorname{News}_{t}+0.1\right)$ & & & & $\begin{array}{c}0.00091^{* * *} \\
(0.00028)\end{array}$ & \\
\hline $\operatorname{Ln}\left(\text { Thai } \text { News }_{t}\right)^{*} \mathrm{D}_{1}$ & & & & & $\begin{array}{l}0.001^{* *} \\
(0.0004) \\
\end{array}$ \\
\hline R-Squared & $0.38 \%$ & $1.68 \%$ & $0.95 \%$ & $1.47 \%$ & $1.07 \%$ \\
\hline Number of Observations & 389 & 389 & 389 & 389 & 389 \\
\hline
\end{tabular}

Note: Robust Standard errors allowing for heteroskedasticity are reported in parentheses.

Volatility is calculated as the $(\log ($ Return Index $t)-\log ($ Return Index t-1) $)$.

$\mathrm{D}_{1}=1$ if Thai News $>0$ and $\mathrm{D}_{1}=0$ if Thai News $=0$

*** Significant at $1 \%,{ }^{* *}$ Significant at $5 \%, *$ Significant at $10 \%$. 
Table 8: Chilean Stock Market Volatility and Thai News

\begin{tabular}{|c|c|c|c|c|c|}
\hline 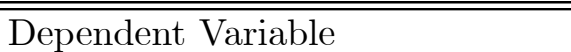 & & & $\overline{\text { Chilean Vola }}$ & $\overline{\text { ility }}$ & \\
\hline & $\begin{array}{l}\text { OLS } \\
(1)\end{array}$ & $\begin{array}{l}\text { OLS } \\
(2)\end{array}$ & $\begin{array}{c}\text { OLS } \\
(3)\end{array}$ & $\begin{array}{c}\text { OLS } \\
(4)\end{array}$ & $\begin{array}{l}\text { OLS } \\
(5)\end{array}$ \\
\hline Thai News $t$ & $\begin{array}{c}0.0001 \\
(0.0001)\end{array}$ & $\begin{array}{c}0.0001 \\
(0.0001)\end{array}$ & $\begin{array}{c}0.0005^{* * *} \\
(0.0002)\end{array}$ & $\begin{array}{c}0.0005^{* * *} \\
(0.0002)\end{array}$ & $\begin{array}{c}0.0005^{* * *} \\
(0.0002)\end{array}$ \\
\hline$\left(\text { Thai } \text { News }_{t}\right)^{2}$ & & & $\begin{array}{c}-0.00003^{* *} \\
(0.000013)\end{array}$ & $\begin{array}{c}-0.00003^{* *} \\
(0.000013)\end{array}$ & $\begin{array}{c}-0.00003^{* *} \\
(0.000014)\end{array}$ \\
\hline $\begin{array}{l}\text { Control Variables? } \\
\text { US Interest Rates } \\
\text { HK dummy } \\
\text { Chilean News } \\
\text { Thai Volatility } t \\
\text { Thai Volatility }_{t-1} \\
\text { Asian Volatility }_{t} \\
\text { Asian Volatility }_{t-1} \\
\end{array}$ & Yes & Yes & Yes & Yes & Yes \\
\hline Chilean Volatility $_{t-1}$ ? & No & Yes & No & Yes & Yes \\
\hline Squared Variables? & No & No & No & No & Yes \\
\hline $\begin{array}{l}\text { F-Statistic for Granger Causality } \\
\text { R-Squared } \\
\text { Number of Observations }\end{array}$ & $\begin{array}{c}9.22 \% \\
388\end{array}$ & $\begin{array}{c}11.7 \% \\
388\end{array}$ & $\begin{array}{c}10.12 \% \\
388\end{array}$ & $\begin{array}{c}3.31^{* *} \\
12.58 \% \\
388\end{array}$ & $\begin{array}{c}3.61^{* *} \\
13.39 \% \\
388\end{array}$ \\
\hline
\end{tabular}

Note: Robust Standard errors allowing for heteroskedasticity are reported in parentheses.

Volatility is calculated as the absolute value of $(\log ($ Return Index $t)-\log ($ Return Index t-1)).

Squared Variables: Chilean News, Thai Volatility t and t-1, Asian Volatility t and t-1.

*** Significant at 1\%,** Significant at 5\%, ${ }^{*}$ Significant at $10 \%$. 
Table 9: Chilean Stock Market Volatility and Thai News

\begin{tabular}{|c|c|c|c|c|c|c|}
\hline 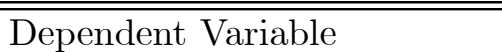 & & & Chilean I & 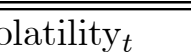 & & \\
\hline Explanatory Variables & $\begin{array}{c}\text { OLS } \\
(1)\end{array}$ & $\begin{array}{l}\text { OLS } \\
(2)\end{array}$ & $\begin{array}{l}\text { OLS } \\
(3)\end{array}$ & $\begin{array}{c}\text { OLS } \\
(4)\end{array}$ & $\begin{array}{c}\text { OLS } \\
(5)\end{array}$ & $\begin{array}{c}\text { OLS } \\
(6)\end{array}$ \\
\hline$\sqrt{\text { Thai News }}$ & $\begin{array}{c}0.0007^{*} \\
(0.00037)\end{array}$ & $\begin{array}{c}0.0007^{*} \\
(0.00036)\end{array}$ & & & & \\
\hline $\operatorname{Ln}\left(\right.$ Thai $\left.\mathrm{News}_{t}+0.1\right)$ & & & $\begin{array}{c}0.0007^{* * *} \\
(0.0002)\end{array}$ & $\begin{array}{c}0.0008^{* * *} \\
(0.0003)\end{array}$ & & \\
\hline $\operatorname{Ln}($ Thai News $t) * D_{1}$ & & & & & $\begin{array}{c}0.0008^{* *} \\
(0.0003)\end{array}$ & $\begin{array}{r}0.0009^{* *} \\
(0.0004)\end{array}$ \\
\hline $\begin{array}{l}\text { Control Variables? } \\
\text { US Interest Rates } \\
\text { HK dummy } \\
\text { Chilean Volatility }_{t-1}\end{array}$ & Yes & Yes & Yes & Yes & Yes & Yes \\
\hline $\begin{array}{l}\text { Linear Controls? } \\
\text { Chilean News } \\
\text { Thai Volatility t and t-1 } \\
\text { Asian Volatility t and t-1 }\end{array}$ & Yes & No & Yes & No & Yes & No \\
\hline $\begin{array}{l}\text { Transformed Controls? } \\
\text { F(Chilean News } \text { N }_{t} \text { ) } \\
\text { F(Thai Volatility) t and } \mathrm{t}-1 \\
\mathrm{~F} \text { (Asian Volatility) } \mathrm{t} \text { and } \mathrm{t}-1\end{array}$ & No & Yes & No & Yes & No & Yes \\
\hline $\begin{array}{l}\text { R-Squared } \\
\text { Number of Observations }\end{array}$ & $\begin{array}{c}12.05 \% \\
388\end{array}$ & $\begin{array}{c}12.22 \% \\
388\end{array}$ & $\begin{array}{c}12.41 \% \\
388\end{array}$ & $\begin{array}{c}12.48 \% \\
388\end{array}$ & $\begin{array}{c}12.17 \% \\
388\end{array}$ & $\begin{array}{c}11.57 \% \\
388\end{array}$ \\
\hline
\end{tabular}

Note: Robust Standard errors allowing for heteroskedasticity are reported in parentheses.

Volatility is calculated as the absolute value of $(\log ($ Return Index $t)-\log ($ Return Index t-1)).

$\mathrm{D}_{1}=1$ if Thai News $>0$ and $\mathrm{D}_{1}=0$ if Thai News $=0$

Transformed Variables: Chilean News, Thai and Asian Volatility same functional form as Thai News.

*** Significant at $1 \%,{ }^{* *}$ Significant at $5 \%,{ }^{*}$ Significant at $10 \%$. 
Table 10: Argentinean Stock Market Volatility and Thai News

\begin{tabular}{|c|c|c|c|c|c|}
\hline \multirow{2}{*}{$\begin{array}{l}\text { Dependent Variable } \\
\text { Explanatory Variables }\end{array}$} & \multicolumn{5}{|c|}{ "Argentinean Volatility ${ }_{t}$} \\
\hline & $\begin{array}{c}\text { OLS } \\
(1)\end{array}$ & $\begin{array}{c}\text { OLS } \\
(2)\end{array}$ & $\begin{array}{c}\text { OLS } \\
(3) \\
\end{array}$ & $\begin{array}{c}\text { OLS } \\
(4) \\
\end{array}$ & $\begin{array}{c}\text { OLS } \\
(5)\end{array}$ \\
\hline Thai News $t$ & $\begin{array}{l}0.00008 \\
(0.0002)\end{array}$ & $\begin{array}{r}-0.00003 \\
(0.0002)\end{array}$ & $\begin{array}{c}0.00037 \\
(0.00038)\end{array}$ & $\begin{array}{l}0.00009 \\
(0.0004)\end{array}$ & $\begin{array}{l}0.00002 \\
(0.0003)\end{array}$ \\
\hline$\left.(\text { Thai News })_{t}\right)^{2}$ & & & $\begin{array}{l}-0.00002 \\
(0.00002)\end{array}$ & $\begin{array}{l}-9.5 \mathrm{E}-06 \\
(0.00002)\end{array}$ & $\begin{array}{c}-4.9 \mathrm{E}-06 \\
(0.000019)\end{array}$ \\
\hline $\begin{array}{l}\text { Control Variables? } \\
\text { US Interest Rates } \\
\text { HK dummy } \\
\text { Thai Volatility }_{t} \\
\text { Thai Volatility }_{t-1} \\
\text { Asian Volatility }_{t} \\
\text { Asian Volatility }_{t-1}\end{array}$ & Yes & Yes & Yes & Yes & Yes \\
\hline Argentinean Volatility ${ }_{t-1}$ ? & No & Yes & No & Yes & Yes \\
\hline Squared Variables? & No & No & No & No & Yes \\
\hline F-Statistic for Granger Causality & & & & 0.25 & 0.12 \\
\hline R-Squared & $12.44 \%$ & $18.83 \%$ & $12.54 \%$ & $18.85 \%$ & $19.36 \%$ \\
\hline Number of Observations & 388 & 388 & 388 & 388 & 388 \\
\hline
\end{tabular}

Note: Robust Standard errors allowing for heteroskedasticity are reported in parentheses.

Volatility is calculated as the absolute value of $(\log ($ Return Index t $)-\log ($ Return Index $t-1))$.

Squared Variables: Thai Volatility t and t-1, Asian Volatility t and t-1.

$* * *$ Significant at $1 \%, * *$ Significant at $5 \%, *$ Significant at $10 \%$. 
Table 11: Robustness of results to other Measures of Volatility

\begin{tabular}{|c|c|c|c|c|c|}
\hline \multirow{2}{*}{ "Dependent Variable } & \multicolumn{5}{|c|}{ Brazilian Volatility $_{t}$} \\
\hline & OLS & OLS & OLS & OLS & OLS \\
\hline Explanatory Variables & $(1)$ & $(2)$ & $(3)$ & $(4)$ & $(5)$ \\
\hline Thai News $t$ & $\begin{array}{l}0.000037^{*} \\
(0.000019)\end{array}$ & $\begin{array}{l}0.00006^{* *} \\
(0.000025)\end{array}$ & & & \\
\hline$\left.(\text { Thai News })_{t}\right)^{2}$ & & $\begin{array}{c}-1.78 \mathrm{E}-06 \\
(1.54 \mathrm{E}-06)\end{array}$ & & & \\
\hline$\sqrt{\text { Thai News }}$ & & & $\begin{array}{c}0.00015^{* *} \\
(0.00007)\end{array}$ & & \\
\hline $\operatorname{Ln}\left(\right.$ Thai $\left.\operatorname{News}_{t}+0.1\right)$ & & & & $\begin{array}{c}0.00014^{* * *} \\
(0.00005)\end{array}$ & \\
\hline $\operatorname{Ln}\left(\right.$ Thai News $\left._{t}\right) * \mathrm{D}_{1}$ & & & & & $\begin{array}{c}0.00016^{* *} \\
(0.00007)\end{array}$ \\
\hline $\begin{array}{l}\text { Control Variables? } \\
\text { US Interest Rates } \\
\text { HK dummy } \\
\text { F(Brazilian News } t) \\
\text { F(Thai Volatility) t and t-1 } \\
\text { F(Asian Volatility) t and t-1 } \\
\text { Brazilian Volatility Lags (3 lags) }\end{array}$ & Yes & Yes & Yes & Yes & Yes \\
\hline R-Squared & $17.54 \%$ & $20.15 \%$ & $18.56 \%$ & $17.63 \%$ & $18.59 \%$ \\
\hline Number of Observations & 386 & 386 & 386 & 386 & 386 \\
\hline
\end{tabular}

Note: Robust Standard errors allowing for heteroskedasticity are reported in parentheses.

Volatility is calculated as the $\left(\log (\right.$ Return Index $t)-\log (\text { Return Index t-1) })^{\wedge} 2$.

$\mathrm{D}_{1}=1$ if Thai News $>0$ and $\mathrm{D}_{1}=0$ if Thai News $=0$

Control Variables: Brazilian News, Thai and Asian Volatility same functional form as Thai News.

*** Significant at $1 \%, * *$ Significant at $5 \%, *$ Significant at $10 \%$. 